\title{
AVALIAÇÃO DAS FRAÇÕES FIBROSA, PROTÉICA E CINZA DO CAPIM TANZÂNIA (Panicum maximum Jacq.) IRRIGADO, COM TRESS INTENSIDADES DE PASTEJO
}

\section{ADRIANA RAMOS DE MIRANDA}

Física

Orientador: Prof. Dr. WILSON ROBERTO SOARES MATTOS

Dissertação apresentada à Escola Superior de Agricultura "Luiz de Queiroz", Universidade de São Paulo, para obtenção do título de Mestre em Agronomia, Área de Concentração: Ciência Animal e Pastagens.

PIRACICABA

Estado de São Paulo - Brasil

Novembro - 2002 


\title{
Dados Internacionais de Catalogaçāo na Publicaçāo (CIP) DIVISĀO DE BIBLIOTECA E DOCUMENTAÇĀO - ESALQ/USP
}

\author{
Miranda, Adriana Ramos de \\ Avaliação das fraçōes fibrosa, protéica e cinza do capim Tanzânia (Panicum maximum \\ Jacq.) irrigado, com três intensidade de pastejo / Adriana Ramos de Miranda. - - \\ Piracicaba, 2002. \\ $47 \mathrm{p}$. \\ Dissertaçaờ (méestrạdộ) Escola Superior de Agricultura Luiz de Queiroz, 2002. \\ Bibliografia. \\ - \\ 1. Capim colonião 2. Cultivo irrigado 3. Espectrofotometria infravermelha 4. Fibra
} 5. Gramínea forrageira 6. Pastejo 7. Pós-pastejo 8. Proteína I. Título

CDD 633.2 
A meus pais Carlos e Hylda dedico com amor 


\section{AGRADECIMENTOS}

Ao Prof. Wilson Mattos pela orientação e apoio.

Ao Eng. Agr. Marco Antonio Balsalobre pela contribuição na realização deste trabalho.

À CAPES pela concessão da bolsa de estudos.

Aos colegas Rafael e Ricardo pela valiosa ajuda na condução dos experimentos realizados.

Aos funcionários do Departamento de Produção Animal pela ajuda e incentivo.

À Claudia pela indispensável colaboração na execução das análises estatísticas.

Às amigas Carolina, Simone, Liliane e Cleide pelo carinho e incentivo. 


\section{SUMÁRIO}

Página

LISTA DE FIGURAS .................................................................. vi

LISTA DE TABELAS....................................................................... vii

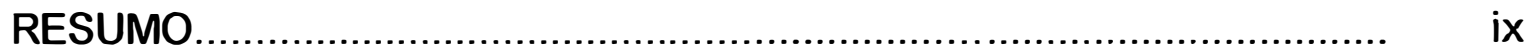

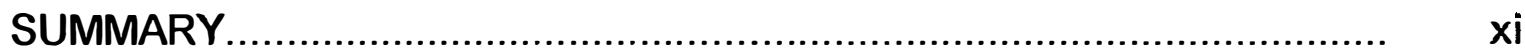

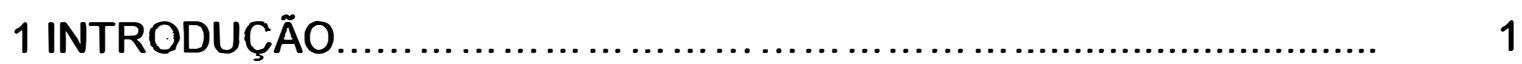

2 REVISÃO DE LITERATURA............................................ 5

2.10 cultivar Tanzânia....................................................................... 5

2.2 A importância do manejo na qualidade da planta................................ 6

2.3 Qualidade e morfologia da planta forrageira..................................... 7

2.4 Composição química...................................................................... 10

2.5 Resíduo pós pastejo.................................................................... 12

2.6 Espectrofotometria de reflectância no infra vermelho

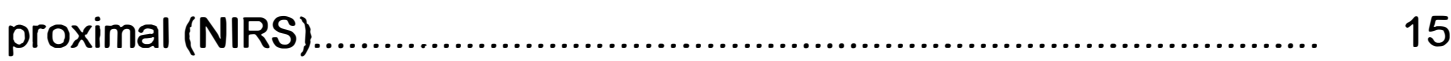

3 MATERIAL E MÉTODOS................................................................ 20

4 RESULTADOS E DISCUSSÃO........................................................ 25

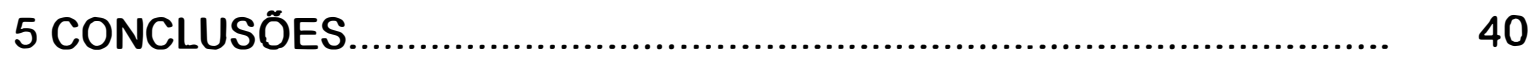

REFERÉNCIAS BIBLIOGRÁFICAS............................................... 41 


\section{LISTA DE FIGURAS}

Página

1 Teores de FDN do capim Tanzânia nos dez ciclos de pastejo............... 28

2 Teores de FDA do capim Tanzânia nos dez ciclos de pastejo................ 29

3 Teores de FDN das quatro partes do capim Tanzânia, nos dez ciclos

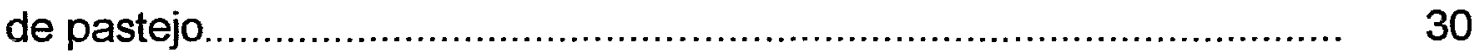

4 Teores de FDA das quatro partes do capim Tanzânia, nos dez ciclos

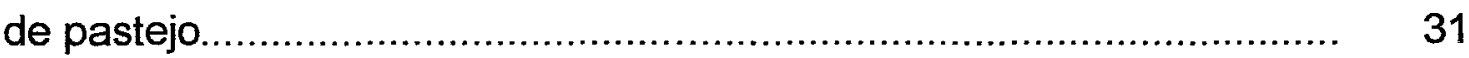

5 Teores de PB do capim Tanzânia nos dez ciclos de pastejo.................. 33

6 Teores de PB das quatro partes do capim Tanzânia, nos dez ciclos

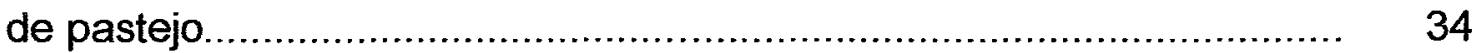

7 Teores de CZ do capim Tanzânia nos dez ciclos de pastejo................. 36 


\section{LISTA DE TABELAS}

Página

1 Datas de início e término dos ciclos de pastejo.................................... 21

2 Resíduo pós pastejo para os três tratamentos considerados, em quatro épocas do ano.

3 Condições climáticas da área experimental ao longo do período de coleta de dados

4 Número e origem das amostras que compõem os cinco bancos de dados utilizados para construção das equações de predição.

5 Valores médios de FDN, FDA, PB e CZ das quatro partes da planta avaliadas nos dez ciclos de pastejo.

6 Teores médios de FDN das quatro partes do capim Tanzânia em cada ciclo de pastejo.

7 Teores médios de FDA das quatro partes do capim Tanzânia em cada ciclo de pastejo..

8 Teores médios de PB das quatro partes do capim Tanzânia em cada ciclo de pastejo.

9 Teores médios de $\mathrm{CZ}$ das quatro partes do capim Tanzânia em cada ciclo de pastejo. 
10 Parâmetros considerados na avaliação das equações finais para FDN, FDA, PB e CZ 


\title{
AVALIAÇÃO DAS FRAÇÕES FIBROSA, PROTÉICA E CINZA DO CAPIM TANZÂNIA (Panicum maximum Jacq.) IRRIGADO, COM TRÊS INTENSIDADES DE PASTEJO
}

\author{
Autora: ADRIANA RAMOS DE MIRANDA \\ Orientador: Prof. Dr. WILSON ROBERTO SOARES MATTOS
}

\section{RESUMO}

Amostras de capim Tanzânia (Panicum maximum Jacq.) estabelecido em área irrigada através de pivô central, foram coletadas e avaliadas segundo a técnica NIRS para FDN, FDA, PB e CZ. Os tratamentos consistiram de três intensidades de pastejo: alta, média e baixa, e para cada tratamento foram alocadas doze parcelas de $1330 \mathrm{~m}^{2}$ distribuídas em quatro blocos, sendo cada parcela subdividida em três piquetes para facilitar o manejo. $O$ ensaio consistiu de dez ciclos de pastejo entre outubro de 1999 e outubro de 2000, e as avaliações foram feitas considerando-se também quatro partes distintas da planta: broto, folha nova, folha velha e haste. As concentrações de FDN e FDA foram significativamente menores $\mathrm{e}$ as de PB significativamente maiores $(P<0,05)$ no tratamento de alta intensidade de pastejo $(64,33 ; 33,37$ e $13,83 \%$ na MS respectivamente) quando comparadas aos valores obtidos nos tratamentos de média (66,52; 34,78 e $12,32 \%$ na MS respectivamente) e baixa $(66,93 ; 35,13$ e $11,96 \%$ na MS respectivamente) intensidade. As maiores concentrações de FDN e FDA e as menores de PB foram encontradas, para 
todos os tratamentos, nos primeiros ciclos de pastejo, que correspondem ao período de primavera e verão. Os valores de FDN obtidos ao longo dos dez ciclos de pastejos demonstram a influencia da elevada participação das hastes a partir do ciclo 4 (meados de fevereiro). Quanto aos teores de PB as quatro partes tiveram comportamento semelhante ao longo dos ciclos de pastejo, sendo que apenas a haste apresentou teores significativamente inferiores deste parâmetro. A técnica NIRS se mostrou satisfatória para predizer os parâmetros bromatológicos analisados. 
FIBROUS, PROTEIN AND ASH FRACTIONS IN TANZANIA GRASS (Panicum maximum Jacq.) FORAGE FROM PASTURES UNDER THREE GRAZING

INTENSITIES

\author{
Author: ADRIANA RAMOS DE MIRANDA \\ Adviser: Prof. Dr. WILSON ROBERTO SOARES MATTOS
}

\title{
SUMMARY
}

Cell wall, protein and ash concentrations were estimated by NIRS on Tanzania grass (Panicum maximum Jacq.) forage, from pastures managed under a central pivot irrigation system. Treatments were three grazing intensities (high, medium and low) distributed into four blocks; for each treatment there were 12 plots of $1330 \mathrm{~m}^{2}$, three in each block. One day before grazing, from October 1999 to October 2000 , one paddock per treatment per block was sampled in ten different sites and the samples were separated into: shoots, new leaves, old leaves and stems. The average concentrations of NDF and ADF were significantly lower and that of CP was significantly higher $(P<0,05)$ in the high intensity treatment $(64,33,33,37$ and $13,83 \%$ of $\mathrm{DM}$, respectively) as compared to the medium $(66,52,34,78$ and $12,32 \%$ of DM, respectively) and low $(66,93$, 35,13 and $11,96 \%$ of DM respectively) intensity. For all treatments, the highest NDF and ADF and the lowest CP concentrations were observed during the Spring and Summer grazing periods. NDF, ADF and protein concentrations showed the same trend over grazing cycles. The ADF and CP concentrations in 
stems over grazing cycles showed higher and lower values, respectively, as compared to the other plant parts, whereas the NDF concentrations did not show this trend. NIRS proved to be a valuable tool to estimate the chemical composition of forage fractions of Tanzania grass. 


\section{INTRODUÇÃO}

Seria original iniciar esta preleção sem falar na tradição e potencial que o Brasil possui de utilizar pastagens como principal fonte de alimento para bovinos. Porém a necessidade de valorizar tal aspecto na produção de ruminantes justifica que a originalidade seja adiada para um momento mais propício.

Com uma área total aproximada de pastagens de 178 milhões de hectares (Pitombo, 1999) o potencial brasileiro de produzir carne e leite a pasto abrange desde sistemas de produção de pequeno porte, restrita capacidade de mecanização e alcance econômico regional, até sistemas de grande porte, alta mecanização e capacidade de atingir mercados externos. Fica assim evidente a necessidade de um profundo conhecimento sobre os fatores que influenciam o potencial de produção de sistemas a pasto, para que se possa elaborar desde a melhor estratégia de manejo até metas de produção e produtividade.

Devido a seu clima tropical e subtropical, o Brasil possui grande potencial de produção de forragem, porém baixíssimos níveis de produtividade ainda caracterizam a pecuária nacional, com números como 0,5 UA/ha. ano de lotação animal, $50 \%$ de natalidade e produção de $55 \mathrm{~kg} / \mathrm{ha}$.ano de carcaça e de $300 \mathrm{~kg} / \mathrm{ha}$.ano de leite (Corsi, 1986). Quando se considera fazendas que exploram pastagens cultivadas para a produção de carne, atualmente estes números ficam entre 75 a $90 \mathrm{~kg} / \mathrm{ha}$.ano de carcaça, ou 150 a $180 \mathrm{~kg} / \mathrm{ha}$.ano de peso vivo (PV) (Aguiar et al., 2001), enquanto encontram-se na literatura produções acima de $900 \mathrm{~kg} / \mathrm{ha}$.ano de PV (Aguiar et al., 2000; Esteves, 
2000; Corsi et al., 2001) indicando uma produtividade muito inferior a seu potencial.

O alto custo da terra, principalmente em regiões de elevado potencial econômico para pecuária e agricultura, juntamente com o alto custo de alimentos concentrados são fatores que pressionam os produtores a adotarem técnicas que propiciem elevadas produções de forragens de alta qualidade, para atender as necessidades de desempenho animal adequado.

Nesse contexto pode-se destacar várias linhas de pesquisa de elevada importância para uma administração adequada das variáveis que influenciam a expressão deste enorme potencial de produção a pasto. Entre elas está, sem dúvida, a compreensão dos problemas associados ao uso de espécies forrageiras que possam satisfazer as necessidades de produção e produtividade características da pecuária brasileira. Para que se possa indicar soluções que minimizem características indesejáveis destas espécies é necessário conhecer profundamente seu comportamento dinâmico, frente a uma determinada situação ambiental de interesse, que pode variar de acordo com o sistema de produção adotado, com características climáticas da região onde o sistema está estabelecido, e outros aspectos.

$\mathrm{Na}$ busca por maior intensificação da atividade alguns produtores utilizam técnicas como a fertilização e, mais recentemente, a irrigação como alternativas para aumentar a produtividade e lucratividade do sistema de produção. Assim torna-se necessário maior conhecimento sobre o comportamento de forrageiras submetidas à tais técnicas, pois já é conhecido que a qualidade da forragem ao longo do ano em áreas irrigadas é diferente quando comparada com pastagens não irrigadas (Balsalobre, 2002).

A determinação da composição bromatológica e digestibilidade das frações que compõem a planta forrageira são de fundamental importância, assim como as variações destes fatores no decorrer do ano, que caracterizam situações ambientais distintas, e interferem intensamente no comportamento tanto quantitativo como qualitativo da planta. 
Muitas plantas forrageiras tropicais tem capacidade de suprir as necessidades prementes do adequado desempenho animal porém são, não raro, suscetíveis a pequenas modificações de manejo. Muitas vezes essa facilidade de resposta ao manejo pode ser revertida em aumento da capacidade de adaptação da planta a um determinado sistema de produção.

O capim Tanzânia (Panicum maximum Jacq.) possui elevado potencial forrageiro, característica já conhecida desde as primeiras pesquisas com 0 gênero Panicum no Brasil, além de grande capacidade de expressão deste potencial quando submetido às condições ambientais do país. Tem sido bem aceito entre os pecuaristas, e um volume não desprezível de trabalhos científicos já indicam algumas características relevantes ao planejamento de sua utilização e à programas de melhoramento, porém ainda são muitos os aspectos de seu comportamento fisiológico que devem ser esclarecidos.

Ao discorrer sobre o erro, ainda nos dias de hoje comum, de se procurar pelo "capim milagroso", isto é, aquele que reúna as características de baixa exigência com relação à fertilidade do solo, resistência ao pastejo, ao pisoteio, ao fogo, satisfatória qualidade nutricional e produtividade na seca, Corsi (1995) destacou que se o esforço iniciado na década de 80 para se pesquisar as espécies do gênero Panicum fosse capaz de estabelecer critérios que atendam as exigências de manejo destas plantas, os sistemas de produção a pasto no Brasil poderiam dar importante passo, podendo optar por um capim de qualidade superior quando comparado às espécies atualmente dominantes na pecuária brasileira.

Foi desse trabalho de pesquisa que surgiu a indicação do cultivar Tanzânia como uma planta de elevado potencial para ser utilizada na pecuária brasileira.

Nesse cenário repleto de características necessárias e altamente valiosas ao aumento da produtividade de nossa pecuária é que um intenso trabalho de pesquisa deve ser continuamente estimulado, a fim de suprir as 
deficiências de domínio e conhecimento, grandes responsáveis pela baixa eficiência da atividade pecuária no Brasil quando se considera seu potencial.

Este trabalho tem por objetivo contribuir para o melhor conhecimento sobre a qualidade do capim Tanzânia no decorrer de seu desenvolvimento, em área irrigada, quando submetido a três intensidades de pastejo rotacionado. Além disso, o trabalho utiliza a técnica de espectrofotometria de reflectância na faixa do infravermelho proximal (NIRS) para estimar alguns parâmetros bromatológicos da forrageira. 


\section{REVISÃO DE LITERATURA}

2.10 cultivar Tanzânia

O capim Tanzânia foi coletado pelo "Institut Français de Recherche Scientifique pour le Développement em Coopération" (ORSTOM) em Korogwe, na Tanzânia, e seu lançamento comercial pela Embrapa como BRA-007218 ocorreu em 1990, após longo trabalho de seleção (Jank et al., 1994; Jank, 1995).

Segundo Savidan et al. (1990) pode-se caracterizar o cv. Tanzânia como planta de crescimento ereto, cespitosa e com altura média de 1,3 m. Folhas decumbentes com largura média de $2,6 \mathrm{~cm}$; lâminas e bainhas glabras sem cerosidade; colmos levemente arroxeados; inflorescências do tipo panícula com ramificações primárias longas e secundárias longas apenas na base; espiguetas arroxeadas, glabras e uniformemente distribuídas; e vertículo glabro.

É uma planta tropical absorvendo assim $\mathrm{CO}_{2}$ do meio através do ciclo C4. Tais plantas são caracterizadas por apresentarem altas taxas de crescimento $e$, com o avanço da idade fisiológica, perdem qualidade mais rápido que plantas que absorvem $\mathrm{CO}_{2}$ através do ciclo $\mathrm{C} 3$ (predominantes em países de clima temperado) (Van Soest, 1982). As plantas caracterizadas por absorverem $\mathrm{CO}_{2}$ através do ciclo $\mathrm{C} 4$ costumam apresentar maiores proporções de parede celular, além de menores teores de proteina, pois por serem mais eficientes na retirada de $\mathrm{CO}_{2}$ do meio possuem menores proporções da enzima 
Rubisco (RuBP carboxilase/oxigenase) que aquelas que utilizam o ciclo C3, apresentando assim menores concentrações de nitrogênio em seus tecidos fotossintéticamente ativos (Balsalobre, 2002).

2.2 A importância do manejo na qualidade da planta

O capim Tanzânia apresenta um comportamento fișiológico que se adapta bem a técnicas de manejo que adotam o sistema rotacionado ou, pelo menos, alternado de uso de pasto, como já indicava Corsi em 1984 ao discorrer sobre variedades de elevada produtividade de Panicum. As características fisiológicas do perfilhamento assim como o fato destas plantas apresentarem elongação das hastes e elevado potencial de produtividade sugerem que um pastejo uniforme, à semelhança de um sistema rotacionado e suas variações, traga benefícios quando comparado ao sistema contínuo, apontando a necessidade de se estudar profundamente aspectos como frequência e altura de corte para que se possa planejar seu manejo.

A composição química das plantas forrageiras é influenciada por diversos fatores como idade, altura de corte, adubação, características morfológicas da planta, fatores ambientais etc.; e encontra-se na literatura evidência da influencia do manejo utilizado na composição química da forragem.

Segundo Balsalobre (1996) o manejo de pastagens baseado na pressão de pastejo pode ser inadequado em áreas intensificadas, pois pressões de pastejo consideradas altas para tais sistemas podem promover altos resíduos de matéria seca verde pós pastejo, ocasionando baixa eficiência de pastejo. Dessa forma, o resíduo de matéria seca verde pós pastejo, ou apenas a altura do pasto na saída dos animais, pode ser um instrumento melhor que a pressão de pastejo no auxílio do manejo adequado da planta forrageira. 
É necessário considerar que plantas manejadas com resíduos pós pastejo mais altos podem perder qualidade ao longo do ano, pois ocorre maior renovação de tecidos nas pastagens manejadas mais baixas. Por outro lado quando o resíduo é mais alto existe maior seletividade pelos animais, o que pode tornar a forragem consumida de tão boa qualidade quanto pastagens manejadas com menor massa de resíduo (Balsalobre, 2002).

O capim Tanzânia tem sido muito estudado com relação a sua fisiologia e manejo, no entanto a associação da produção, manejo e qualidade da forragem precisa ser melhor definida (Balsalobre, 2002).

2.3 Qualidade e morfologia da planta forrageira

O capim Tanzânia floresce normalmente no outono (abril/maio), e durante este processo ocorre o alongamento das hastes, que exercem um efeito negativo sobre o valor alimentar da forragem (Santos, 2002).

Segundo Corsi (1995) a presença da haste determina o declínio acentuado da digestibilidade de gramíneas tropicais, por outro lado parece ser imprescindivel para manter elevada sua produtividade. Quanto às espécies de Panicum pode-se notar esta característica ao se observar a coleção de 156 ecotipos do banco de germoplasma do CNPGC (Centro Nacional de Pesquisa de Gado de Corte), origem do cultivar Tanzânia lançado em 1990, fato que indica o alongamento das hastes como uma característica que deve ser cuidadosamente estudada, por estar provavelmente profundamente relacionada ao comportamento fisiológico da planta, considerando que se apresenta de maneira generalizada na espécie.

Alguns trabalhos de fisiologia de plantas forrageiras apontam as hastes como necessárias para possibilitar elevada produtividade. Assim, para manter ou elevar o potencial produtivo de forrageiras tropicais é necessário dirigir esforços no sentido de aproveitar a variabilidade genética quanto à 
digestibilidade das hastes. Esse componente da forragem além de representar parte significativa da produção de matéria seca, não deve ser eliminado e/ou reduzido pelos programas de melhoramento sem avaliações cuidadosas, que possam indicar seu comportamento não só quantitativo como também qualitativo, no decorrer do desenvolvimento da planta (Corsi, 1995).

A importância de se controlar a produção de hastes no pasto vem sendo ressaltada há vários anos por muitos pesquisadores. Segundo Balsalobre (2002) a presença de hastes pode reduzir a eficiência do sistema de duas formas: limitando a capacidade de colheita da forragem pelo animal e reduzindo seu valor alimentar.

Santos (1997) indicou o controle do desenvolvimento das hastes como um dos principais objetivos a serem atingidos no manejo de pastagens do capim Tanzânia. Como destacado por Hume, citado por Santos et al. (2001), trabalhos com plantas temperadas têm utilizado informações sobre a dinâmica de perfilhamento para o planejamento de cortes estratégicos com o objetivo de controlar o florescimento da planta forrageira sem comprometer a perenidade do pasto.

No Brasil Central os meses secos do ano coincidem com os meses mais frios. Em áreas irrigadas, apesar do suprimento de água, a planta irá crescer a menores taxas devido à menor luminosidade e temperatura, o que poderá resultar, nesse período, em plantas mais tenras e de melhor qualidade. O florescimento destas plantas pode ser responsivo a um hidroperíodo, podendo ocorrer alterações na fisiologia do florescimento devido à irrigação. Assim, pastagens irrigadas podem apresentar diferenças em qualidade ao longo do ano, quando comparadas com plantas não irrigadas (Balsalobre, 2002).

Com o objetivo de quantificar a participação das gerações de perfilhos na produção do capim Tanzânia, e determinar se esta contribuição vem predominantemente do acúmulo de hastes ou de folhas, num experimento conduzido com três intensidades de pastejo (no qual as unidades experimentais 
eram as mesmas utilizadas pelo ensaio que originou esta dissertação), Santos et al. (2001) concluíram que não há um grupo específico de perfilhos que seja responsável pelo aumento da proporção de hastes. Porém os pesquisadores detectaram que em abril/maio as hastes representavam cerca de $70 \%$ da massa de forragem, sendo que as três primeiras gerações de perfilhos foram responsáveis por 44,54 e $64 \%$ da produção de hastes nos tratamentos de alta, média e baixa intensidade de pastejo, respectivamente. Assim os autores consideraram que para se reduzir os efeitos negativos do florescimento sobre a qualidade da forragem, seria interessante promover maior renovação da população de perfilhos a partir de março, quando o aumento da produção de hastes na massa de forragem se torna evidente (Santos et al., 2001).

Barbosa R. A. et al. (2001) conduziram um ensaio com o objetivo de avaliar a influência da intensidade de pastejo na dinâmica de crescimento do capim Tanzânia, através de características morfogênicas da planta, observando perfilhos novos e remanescentes de dosséis submetidos a dois resíduos pós pastejo (3,6 e 2,3 t de MS/ha). Estimando taxa de alongamento foliar (TAL), duração de alongamento (DAL), taxa de senescência (TS), comprimento final de lâmina foliar (CF) e taxa de aparecimento de folhas (TAP), os autores obtiveram resultados que indicaram TAP e DAL como as características mais influenciadas pela intensidade de pastejo e tipo de perfilho, enquanto TAL e TS não diferiram para ambos os parâmetros. O CF médio por perfilho aos 35 dias não diferiu entre tratamentos mas foi maior para os perfilhos remanescentes; a TAP nos perfilhos novos foi maior no tratamento de alta intensidade de pastejo, assim como para perfilhos remanescentes; e DAL foi menor para alta intensidade e perfilhos novos. Assim, o resíduo baixo promoveu maior quantidade de folhas novas com menor tempo de alongamento, e os autores concluíram que as diferenças no CF podem ser atribuídas aos valores da taxa de aparecimento de folhas, onde maiores valores de TAP tendem a produzir maior número de folhas curtas por perfilho e um incremento no número de perfilhos. 
Num experimento conduzido com o objetivo de avaliar o efeito de diferentes épocas de aplicação do nitrogênio $(N)$ em relação à desfolha sobre o número e peso de perfilhos do capim Tanzânia irrigado, Menezes et al. (2001a) analisaram os dados obtidos em quatro cortes durante o verão. Os autores observaram que as diferenças de aplicação do adubo não provocaram efeito sobre o peso e número de perfilhos porém, as épocas de desfolha tiveram efeito significativo sobre estas variáveis, sendo que no ciclo de desfolha correspondente aos meses de novembro/dezembro havia maior população de perfilhos de menor peso. Tal fato é consistente com grande número de informações encontradas na literatura associando maior população de perfilhos com perfilhos menores.

\subsection{Composição química}

É preciso considerar as diferenças dos vários componentes morfológicos da planta, observando que estes apresentam composição química distinta e são ingeridos e digeridos de forma também distinta (Abrahão, 1996).

$A$ adoção do pastejo rotacionado é bastante eficiente no sentido de amenizar a influencia de fatores que alteram significativamente a qualidade da planta em sistemas de pastejo contínuo porém, mesmo tendo o pastejo rotacionado como base do manejo da pastagem a qualidade da planta se altera no decorrer do ano, e um exemplo deste fato em pastagens de capim Tanzânia pode ser observado no trabalho de Santos (1997), onde ocorreu queda da qualidade da planta a partir do mês de maio, para períodos de descanso de 28 , 38 e 48 dias. Segundo Balsalobre (2002) o decréscimo na qualidade da planta após o outono se dá provavelmente devido a seu florescimento.

Twuidwell et al. (1988), trabalhando com Panicum virgatum L. em três estágios de florescimento reportaram que a qualidade da haste se reduz significativamente após o florescimento. Maiores teores de fibra em detergente 
neutro (FDN) 'e lignina foram observados após o florescimento, e estágios fisiológicos mais avançados foram caracterizados por redução na degradação da matéria seca (MS), na taxa de digestibilidade da FDN, e menor extensão de degradação da FDN das hastes. Para as lâminas foliares não houve aumento no teor de FDN e lignina com o aumento da proporção de inflorescência, porém a digestibilidade da MS e a extensão de degradação da FDN foram menores com o avanço da idade da planta.

$O$ estresse hídrico pode promover aumento na qualidade da forragem, aumentando a digestibilidade da MS e reduzindo a relação haste/folha (Vough et al., 1971; Halim et al., 1989). Porém, em condições de Brasil Central onde o inverno é caracterizado por baixa precipitação pluviométrica, o efeito negativo do florescimento parece ser maior que o efeito benéfico do estresse hídrico, pois a qualidade da planta é sensivelmente reduzida neste período (Santos, 1997).

À medida que a idade fisiológica da planta avança aumentam as porcentagens de hemicelulose, celulose e lignina, reduzindo assim a proporção de conteúdo celular. O teor de proteína, lipídeos e minerais tende a se reduzir, principalmente após o florescimento (Balsalobre, 2002).

As plantas do gênero Cynodon são caracterizadas por altas proporções de FDN (eventualmente menores que 75\%) porém apresentam teores de lignina relativamente baixos (Pedreira et al., 2000). É unânime na literatura considerar que forragens que apresentam baixos valores de lignina em relação a FDN possuem alta qualidade de parede celular, capaz de refletir desempenho adequado em animais pastejando tal forragem.

As gramíneas tropicais apresentam baixos teores de carboidratos solúveis e amido, raramente superiores a $20 \%$ dos carboidratos totais (Vieira et al., 2000). Segundo Balsalobre (2002) pode-se dizer que, dentre os carboidratos estruturais, a hemicelulose possui a maior taxa de fermentação ruminal, fato que ressalta a importância da relação lignina/FDN, pois forragens 
que apresentam baixos valores de lignina em relação a FDN disponibilizam altas proporções de hemicelulose para a fermentação ruminal.

A qualidade da planta forrageira deve ser analisada não somente em relação às alterações na parede celular, mas também em relação à porção protéica porém, novamente é restrito o número de trabalhos que avalia tal aspecto para o capim Tanzânia.

Gerdes et al. (2000) observaram grandes diferenças nos teores de proteína bruta (PB) e FDN de lâminas e hastes do capim Tanzânia, que apresentaram respectivamente 15,3 e $7,5 \%$ de PB e 73,78 e $77,83 \%$ de FDN durante a primavera; os mesmos autores registraram pequena redução da digestibilidade in vitro da matéria seca (DIVMS) dos colmos em relação às lâminas - 55,74 e 56,98\% respectivamente.

Num trabalho conduzido com o objetivo de avaliar os teores de PB, FDN e fibra em detergente ácido (FDA) do capim Tanzânia, manejado em diferentes alturas pós pastejo $(24,26,43,45,52,62,73$ e $78 \mathrm{~cm})$, Rego et al. (2001) concluíram que o aumento na altura do pasto acarretou em forragem de qualidade inferior com menores teores de PB e maiores teores de FDN e FDA.

\subsection{Resíduo pós pastejo}

São muitos os trabalhos na literatura que discorrem sobre a relação do resíduo pós pastejo e desempenho animal. A grande maioria destes trabalhos relacionam maiores resíduos pós pastejo com elevação no desempenho animal, seja este resíduo medido em altura (Hodgson et al., 1994) ou em massa de forragem (Holmes et al., 1984; Almeida, 2000). Porém deve-se considerar que esta relação não é linear e sua curva possui uma assíntota, isto é, após um certo ponto aumentos no resíduo não acarretam incremento algum no desempenho animal. Este ponto crítico na curva varia não somente com características genéticas da planta mas também com características 
ambientais, entre outros fatores. Além disso, como já foi discutido anteriormente, com o aumento da idade da planta, a qualidade nutricional desta decresce, assim aumentos significativos do resíduo pós pastejo ocasionarão queda no desempenho individual quando mantida a lotação. Segundo Balsalobre (2002) resíduos maiores promovem menores lotações com mesmo desempenho por animal, ou seja, menor ganho por área.

O conhecimento detalhado dessa relação assintótica entre o consumo de forragem e o resíduo pós pastejo, permite o planejamento de sistemas de criação a pasto mais eficientes, tanto na utilização da forragem disponível como no desempenho animal, resultando em aumento da produtividade.

Trabalhos realizados com gramíneas temperadas indicam que a quantidade de resíduo pós pastejo interfere significativamente sobre o consumo animal. Holmes et al. (1984) registraram aumento do consumo de vacas em lactação de 2,5 para $4,8 \%$ do peso vivo, quando o resíduo pós pastejo passou de 800 para $1.800 \mathrm{~kg}$ de MS/ha.

Vários trabalhos científicos indicam que o tempo de pastejo do animal durante o dia pode ser bastante reduzido nas épocas do ano de elevada temperatura. Também o número de bocados por hora que o animal é capaz de executar apresenta um limite máximo. A quantidade de forragem apreendida em cada bocado é função do volume do bocado e da densidade da forragem que está sendo pastejada; o volume do bocado por sua vez é função da profundidade do bocado no dossel, multiplicado pela área que esse bocado consegue atingir (Burlison et al., 1991).

Hodgson et al. (1994) apresentaram o conceito de proporcionalidade constante de remoção de forragem propondo que cada bocado tem uma altura constante e proporcional à altura da pastagem. E segundo Burlison et al. (1991) o tamanho do bocado tem uma relação linear positiva com o a altura da planta.

Porém, segundo Laca et al. citados por Balsalobre (2002) o comportamento do tamanho do bocado com relação à altura da planta é representado por uma curva assintótica, de tal forma que o aumento da 
profundidade do bocado, correspondente a uma unidade de aumento da altura da planta, diminui com o aumento da altura da planta até um limite a partir do qual aumento na altura da planta não acarreta nenhum incremento na profundidade do bocado.

Segundo Mitchell et al. (1993) a densidade da forragem está diretamente relacionada com a área de bocado, sendo esse efeito mais importante em forragens de alta densidade.

Animais pastejando capim Tanzânia em três alturas: $53 ; 68$ e $75 \mathrm{~cm}$ (média de três dias de pastejo) Costa et al. (2001) não encontraram diferenças na taxa de bocados, porém no tratamento correspondente à menor altura da planta o tempo de pastejo foi maior, indicando provavelmente uma forma dos animais compensarem o menor tamanho de bocado devido a menor altura da planta.

Num experimento no qual se mediu tempo de bocado de ovelhas pastejando capim Tanzânia manejado em três resíduos pós pastejo: baixo (15 $\mathrm{cm})$, médio $(24 \mathrm{~cm})$ e alto $(60 \mathrm{~cm})$, que representam massa de forragem de $2.673,2.981$ e $4.255 \mathrm{~kg}$ de MS/ha respectivamente, Carvalho et al. (2001) registraram aumento no tempo de cada bocado de $1,85^{\prime \prime}$, para o resíduo baixo, para 2,55" para o resíduo alto, concluindo assim que, mesmo o tamanho de bocado sendo maior, quando a altura da planta é maior, a menor taxa de ingestão pode levar a menores consumos em situações de maior disponibilidade de forragem.

Já foi destacado que pastagens manejadas em menores alturas podem apresentar melhor qualidade nutricional, explicada pela maior renovação da população de perfilhos. Santos et al. (2001) ao conduzirem um experimento com o objetivo de avaliar a participação de gerações de perfilhos na produção do capim Tanzânia, observaram uma tendência de maior renovação da população de perfilhos no tratamento de maior intensidade de pastejo avaliada. As parcelas foram pastejadas em sistema rotacionado e a amostragem feita um dia antes de cada pastejo. Os autores registraram 11,30 e $37 \%$ de perfilhos 
com mais de 99 dias de idade e 59, 50 e 39\% de perfilhos com menos de 66 dias para os tratamentos de alta, média e baixa intensidade de pastejo respectivamente.

Clliers et al. citados por Balsalobre (2002) verificaram melhor qualidade da forragem em menores alturas de resíduo pós pastejo promovida pela maior lotação animal (0,52, 0,78 e 1,56 UA/ha). A maior lotação provocou menor ganho de peso individual $(0,99,0,68$ e $0,25 \mathrm{~kg} /$ dia/cabeça), porém a lotação intermediária promoveu os maiores ganhos de carcaça por unidade de área $(70,9,81,4$ e 59,4 kg/ha).

Outra explicação possivel da melhor qualidade nutricional observada em pastagens de capim Tanzânia manejadas em menores alturas é a elevação da proporção de folhas. Aguiar et al. (2001) trabalhando com três resíduos pós pastejo obtiveram maior proporção de folhas e de folhas novas para o menor residuo.

2.6 Espectrofotometria de reflectância no infravermelho proximal (NIRS)

As técnicas de análise bromatológica de forragens, assim como a análise química convencional de qualquer material orgânico, são caracterizadas, sem exceção, pela manipulação de reagentes químicos em grande parte perigosos à saúde humana e ao meio ambiente, além de envolverem rotinas trabalhosas e longas.

O desenvolvimento da programação computacional, e com isso a facilidade de acesso à poderosos programas de estatística, vem beneficiando muito a área da química analítica, viabilizando a utilização de técnicas como a quimiometria.

Segundo Kowalski (1977) a quimiometria é uma área da química que utiliza a energia luminosa, a matemática e a estatística para predizer a composição de um composto. Trabalhando com tais ingredientes a 
espectrofotometria de reflectância no infravermelho proximal tem se mostrado poderoso instrumento da análise química de materiais orgânicos.

Como já citado anteriormente, o conhecimento da composição química da forragem é essencial para a análise de seu potencial e planejamento de seu manejo e utilização; além disso, seria trivial concluir-se que o tempo e quantidade de amostra necessária para uma análise qualitativa influem intensamente no benefício potencial deste conhecimento. Não só a produção científica, que necessita de um elevado número de repetições experimentais para compor uma base de referência para uma determinada área do conhecimento, como também a utilização de técnicas de análise aplicada à rotina da economia ativa, são extremamente beneficiadas pela diminuição do tempo de análise e quantidade de amostra necessária.

A espectrofotometria de reflectância aplicada à análise de produtos agrícolas foi inicialmente utilizada para predizer rapidamente o conteúdo de óleo, proteína e umidade de grãos em sementes de oleaginosas (Norris et al., 1965; Bem Gera et al., 1968; Hymovitz et al., 1974; Rine et al., 1975). Posteriormente Norris et al. (1976) publicaram o primeiro trabalho aplicando a técnica a forragens, e depois de dois anos foi iniciado um trabalho conjunto, de âmbito nacional, no território norte-americano, apresentado posteriormente por Templeton et al. em 1983. Em 1985 foi publicada a linha base para análise de forragens através da espectrofotometria de reflectância no infravermelho proximal pelo Departamento de Agricultura dos Estados Unidos da América, e em 1989 o material foi reeditado com suplementos.

A técnica da NIRS se baseia na utilização de curvas espectrais do material analisado. As ligações atômicas e moleculares vibram com amplitudes e frequências características de cada ligação, e a detecção da radiação refletida por material orgânico na faixa do infravermelho proximal (800 a $2.500 \mathrm{~nm}$ ) caracteriza de forma satisfatória o material com relação às ligações do tipo $\mathrm{CH}$, $\mathrm{NH}$ e $\mathrm{OH}$ principalmente, que por sua vez tem elevada correlação com características bromatológicas de forragens. 
Atualmente existe grande variedade de modelos do equipamento utilizado para a aplicação da técnica da espectrofotometria de reflectância, indicados para objetivos distintos. Na sua totalidade, os vários modelos de equipamentos destinados à aplicação da técnica da NIRS dispõe de detectores (operantes na faixa do infravermelho proximal) e de uma lâmpada que faz uma luz branca incidir sobre a amostra, que por sua vez deve ser interiorizada no equipamento em um suporte apropriado, chamado de célula, que possui pelo menos um lado de vidro transparente. A localização e número de detectores podem variar mas estão diretamente relacionados com características do programa estatístico e do suporte computacional vinculados ao equipamento.

As informações coletadas pelos detectores, isto é, a energia refletida pela amostra, é usualmente armazenada na forma logarítmica (como $\log (1 / R$ ) onde R é a energia refletida). Segundo Vogel (1992) e Shenk et al. (1994) a aplicação do logaritmo permite obter curvas comparáveis com a absorção que possui relação linear com a composição química.

Os programas estatísticos utilizados constróem uma rede de parâmetros associativos entre o espectro de uma determinada amostra e os valores referentes à sua análise bromatológica convencional. Assim, o banco de dados composto pelo espectro e pelos valores numéricos referentes às análises bromatológicas convencionais de interesse, gera um algoritmo capaz de predizer a composição bromatológica de uma amostra "irmã" das amostras geradoras do banco de dados, ao ter seu espectro coletado.

$\mathrm{O}$ algoritmo resulta, em último estágio, de uma equação que é tão mais precisa quanto maior o número de amostras que compõem o banco de dados gerador e maior sua variabilidade espectral. A caracterização rígida da espécie e cultivar das amostras geradoras do banco de dados é muitas vezes utilizada, porém sua necessidade não foi comprovada e o aumento da amplitude espectral de bancos de dados compostos por espécies e cultivares de forragens diferentes, que tenham características bromatológicas comuns, podem trazer benefícios ao resultado e utilização da técnica que devem ser 
considerados. A amostra que deverá ter sua composição bromatológica predita pela equação deve respeitar as características utilizadas para a seleção das amostras que compuseram o banco de dados gerador (como por exemplo, gênero, espécie, idade fisiológica etc.).

O processo descrito acima é usualmente chamado de calibração do equipamento, que nada mais é que a criação de um modelo matemático que descreve a composição química de uma amostra submetida a radiação, a partir da absorção da energia na faixa do infravermelho proximal (Pires, 1996).

Se a medida do sinal for afetada por um único componente pode-se utilizar um modelo de regressão linear simples porém, segundo Pires (1996), a melhor resposta é obtida através de modelos de regressões lineares múltiplas, que combinam diferentes variáveis e reduzem o erro devido ao acaso na obtenção das equações de calibração.

Alguns autores (Willians, 1975; Norris et al., 1984; Cowe et al., 1985 entre outros) indicam o tamanho de partícula (densidade e orientação) da amostra como um fator de elevada influência no erro da análise bromatológica via NIRS. Porém tais efeitos podem ser minimizados através de modelos matemáticos adequados (já presentes nos softwares que acompanham os equipamentos). Além disso, recomenda-se trabalhar com amostras secas e moídas a um milimetro (Abrams, 1989; Shenk et al., 1992; Willians, 1992; Shenk et al., 1994), a fim de reduzir e uniformizar o tamanho de partícula.

Os programas estatísticos que acompanham tais equipamentos permitem a aplicação de elevado número de tratamentos matemáticos, que podem diferir também por um elevado número de parâmetros. Assim é necessário dispor de critérios de avaliação para optar pela equação que melhor prediz a composição bromatológica de uma amostra. Os parâmetros mais comumente utilizados nesta avaliação da equação de calibração são o erro padrão da calibração, isto é, o desvio padrão da diferença entre o valor predito e o informado como referência, e o coeficiente de correlação (simples ou múltipla) (Pires, 1996); sendo que o erro padrão de calibração é desejado o 
mais baixo possível enquanto o coeficiente de correlação o mais próximo de um. 


\section{MATERIAL E MÉTODOS}

O experimento foi conduzido na Fazenda Areão da Escola Superior de Agricultura "Luiz de Queiroz" da Universidade de São Paulo, situada na cidade de Piracicaba, estado de São Paulo (22 $42^{\prime} 30^{\prime \prime}$ lat. S; $47^{\circ} 38^{\prime} 00^{\prime \prime}$ long. W; $546 \mathrm{~m}$ de altitude).

A forragem utilizada foi o capim Tanzânia (Panicum maximum Jacq.) estabelecido em área irrigada através de pivô central. A pastagem foi formada em abril de 1999 e o primeiro pastejo ocorreu em agosto deste mesmo ano. Outros dois pastejos destinados ao estabelecimento dos tratamentos se sucederam, e em outubro de 1999 ocorreu o primeiro pastejo com efetivo levantamento de dados. O último levantamento de dados considerado neste trabalho é referente ao décimo ciclo de pastejo, que teve seu término em outubro de 2000 (Tabela 1). Os animais utilizados foram machos da raça nelore com cerca de 10 meses de idade. 
Tabela 1. Datas de início e término dos ciclos de pastejo.

\begin{tabular}{ccc}
\hline Ciclo de pastejo & Início & Término \\
\hline 1 & $29 / 10 / 99$ & $04 / 12 / 99$ \\
2 & $04 / 12 / 99$ & $09 / 01 / 00$ \\
3 & $09 / 01 / 00$ & $14 / 02 / 00$ \\
4 & $14 / 02 / 00$ & $21 / 03 / 00$ \\
5 & $21 / 03 / 00$ & $26 / 04 / 00$ \\
6 & $26 / 04 / 00$ & $02 / 06 / 00$ \\
7 & $02 / 06 / 00$ & $08 / 07 / 00$ \\
8 & $08 / 07 / 00$ & $13 / 08 / 00$ \\
9 & $13 / 08 / 00$ & $18 / 09 / 00$ \\
10 & $18 / 09 / 00$ & $24 / 10 / 00$ \\
\hline
\end{tabular}

Os tratamentos consistiram de três intensidades de pastejo: alta, média e baixa, caracterizadas por resíduos pós pastejo que variaram de acordo com a época do ano, e estão representados na Tabela 2.

Tabela 2. Resíduo pós pastejo para os três tratamentos considerados, em quatro épocas do ano.

\begin{tabular}{ccccc}
\hline Tratamento & Época 1 & Época 2 & Época 3 & Época 4 \\
\hline & $1277^{\mathrm{Aab}}$ & $1763^{\mathrm{Aab}}$ & $816^{\mathrm{Ab}}$ & $1210^{\mathrm{Aba}}$ \\
Intensidade alta & $3456^{\mathrm{Bb}}$ & $3346^{\mathrm{Bb}}$ & $2548^{\mathrm{Bab}}$ & $3306^{\mathrm{Bb}}$ \\
Intensidade média & $2459^{\mathrm{Ba}}$ & $5335^{\mathrm{Cb}}$ & $3113^{\mathrm{Ca}}$ & $5471^{\mathrm{Cb}}$ \\
\hline Intensidade baixa & $3106^{\mathrm{Ca}}$ & &
\end{tabular}

Época 1: 29/10/99 a 14/02/00; época 2: $15 / 02 / 00$ a 02/06/00; época 3: 03/06/00 a 18/09/00; época 4: 19/09/00 a 29/11/00.

Médias seguidas da mesma letra minúscula na linha ou maiúscula na coluna não diferem significativamente pelo teste de Tukey $(P>0,05)$.

Fonte: Balsalobre, 2002. 
O manejo adotado em cada ciclo de pastejo foi o pastejo rotacionado com 33 dias de descanso e 3 dias de ocupação. Para cada tratamento foram alocadas doze parcelas de $1330 \mathrm{~m}^{2}$ distribuídas em quatro blocos, sendo cada parcela subdividida em três piquetes para facilitar o manejo.

O solo foi corrigido para garantir os seguintes níveis de fertilidade: saturação por bases de $80 \%$; fósforo a $30 \mathrm{mg} / \mathrm{dm}^{3}$; potássio a $5 \%$ da CTC. A área foi adubada, imediatamente após cada pastejo, em todos os ciclos de pastejo ao longo do ano, com $80 \mathrm{~kg} / \mathrm{ha}$ de $\mathrm{N}$ e $80 \mathrm{~kg} / \mathrm{ha}$ de $\mathrm{K}_{2} \mathrm{O}$.

As condições climáticas durante o período experimental constam da Tabela 3.

Tabela 3. Condições climáticas da área experimental ao longo do período de coleta de dados.

\begin{tabular}{ccccc}
\hline Mês/ano & $\begin{array}{c}\text { Radiação global } \\
(\text { cal/cm }\end{array}$ & $\begin{array}{c}\text { Insolação } \\
(\mathrm{h} / \text { dia })\end{array}$ & $\begin{array}{c}\text { Temperatura } \\
\text { máxima }\left({ }^{\circ} \mathrm{C}\right)\end{array}$ & $\begin{array}{c}\text { Temperatura } \\
\text { mínima }\left({ }^{\circ} \mathrm{C}\right)\end{array}$ \\
\hline Out/99 & 454 & 6,98 & 28,48 & 15,36 \\
Nov/99 & 478 & 7,04 & 29,47 & 15,70 \\
Dez/99 & 508 & 7,23 & 30,56 & 18,99 \\
Jan/00 & 464 & 6,37 & 30,22 & 19,09 \\
Fev/00 & 450 & 5,49 & 29,92 & 19,24 \\
Mar/00 & 411 & 5,42 & 29,68 & 18,53 \\
Abr/00 & 451 & 9,08 & 29,36 & 14,48 \\
Mai/00 & 347 & 7,36 & 26,64 & 11,19 \\
Jun/00 & 304 & 6,68 & 27,16 & 11,36 \\
Jul/00 & 320 & 6,47 & 24,71 & 8,83 \\
Ago/00 & 324 & 5,74 & 26,53 & 12,50 \\
Set/00 & 396 & 6,17 & 27,20 & 15,10 \\
Out/00 & 480 & 7,20 & 32,07 & 17,99 \\
\hline
\end{tabular}


As amostras de forragem foram coletadas de um piquete de cada tratamento, em cada bloco, ao longo de dez ciclos de pastejo. Os blocos foram pastejados em sequência, resultando numa frequência de amostragem de 9 dias. As amostras eram coletadas um dia antes da entrada dos animais no piquete, e a unidade de coleta foram perfilhos de touceiras em dez pontos distintos. A forragem amostrada foi separada em 4 frações: broto (B) - folha sem lígula (não expandida); folha nova (FN) - referente às duas primeiras folhas expandidas; folha velha (FV) - todas as folhas que estavam abaixo das duas primeiras; e haste $(H)$ - referente ao caule e bainha da folha. Após a separação o material era colocado em estufa a $55^{\circ} \mathrm{C}$ com ventilação forçada até peso constante.

As determinações de FDN, FDA, cinza (CZ) e PB foram realizadas através de espectrofotometria de reflectância na faixa do infravermelho proximal. O equipamento utilizado foi um Foss NIRSystems modelo 5000 , com uma amplitude de detecção entre 1100 e $2500 \mathrm{~nm}$ de comprimento de onda. A capacidade máxima de detecção de informação do equipamento corresponde a um intervalo de $2 \mathrm{~nm}$, e foi a utilizada para armazenar os espectros.

As equações de predição utilizadas foram construídas com base em cinco bancos de dados distintos pertencentes ao Laboratório de Bromatologia do Departamento de Produção Animal da ESALQ/USP, referentes a ensaios realizados no próprio Departamento.

As determinações de lignina e DIVMS foram desprezadas, pois os bancos de dados disponiveis geraram péssimas equações para tais parâmetros.

Dois dos cinco bancos de dados utilizados são constituídos de análises de planta inteira de milho, um terceiro banco de dados é formado por forragem do gênero Cynodon, o quarto banco de dados é composto por amostras do cultivar Tanzânia, retiradas das mesmas unidades experimentais utilizadas no experimento que deu origem a esta dissertação, oriundas de um ensaio que ocorreu paralelamente, e o último banco de dados utilizado é o 
resultado da junção dos quatro bancos de dados descritos anteriormente, após a retirada de espectros que estavam fora da amplitude espectral comum aos quatro bancos de dados. O número de amostras que compõe cada banco de dados e sua origem estão descritos na Tabela 4.

Tabela 4. Número e origem das amostras que compõem os cinco bancos de dados utilizados para construção das equações de predição.

\begin{tabular}{ccc}
\hline Banco de dados & Número de amostras & Origem \\
\hline A & 758 & Híbridos de milho \\
B & 267 & Híbridos de milho \\
C & 427 & Cynodon \\
D & 129 & cv. Tanzânia (Panicum) \\
E & 1.543 & Junção dos anteriores \\
\hline
\end{tabular}

Todos os tratamentos matemáticos disponiveis no software foram utilizados e a melhor equação, correspondente a cada banco de dados, foi escolhida através dos parâmetros:

N' - número de amostras utilizadas para o desenvolvimento da equação;

SECV - erro padrão da validação cruzada, ou diferença média entre os valores referentes à análise convencional e os preditos pela equação, das amostras que foram descartadas para o desenvolvimento da equação;

1-VR - onde VR é a variância;

$\mathrm{R}^{2}$ - onde $\mathrm{R}$ é o coeficiente de correlação da regressão linear múltipla;

SEC - erro padrão das amostras utilizadas para o desenvolvimento da equação.

A análise estatistica final foi feita através do pacote estatístico do programa SAS, pelo procedimento MIXED, segundo um modelo de medidas repetidas no tempo. 


\section{RESULTADOS E DISCUSSÃO}

Como citado anteriormente, os bancos de dados utilizados não dispunham de informação satisfatória para construção de boas equações de predição para lignina e DIVMS. Um número muito pequeno de amostras analisadas de forma convencional para estes parâmetros, aliado a uma variabilidade espectral muito grande, acarretou elevada imprecisão das equações. Assim os teores de lignina e DIVMS não foram considerados para avaliação.

Para todos os parâmetros analisados (FDN, FDA, PB e CZ) não foi encontrada diferença entre os tratamentos de média e baixa intensidade de pastejo. No entanto o tratamento de mais alta intensidade de pastejo (baixo resíduo pós pastejo) apresentou menores teores de FDN e FDA, e maiores teores de PB, caracterizando forragem de melhor qualidade considerando-se os dez ciclos de pastejo avaliados (Tabela 5).

Tabela 5. Valores médios de FDN, FDA, PB e CZ das quatro partes da planta avaliadas nos dez ciclos de pastejo.

\begin{tabular}{cccc}
\hline & alta & $\begin{array}{c}\text { Intensidade } \\
\text { média }\end{array}$ & baixa \\
\hline FDN & $64,33^{\mathrm{a}}$ & $\begin{array}{c}\%_{\text {da MS }} \\
66,52^{\mathrm{b}}\end{array}$ & $66,93^{\mathrm{b}}$ \\
FDA & $33,37^{\mathrm{a}}$ & $34,78^{\mathrm{b}}$ & $35,13^{\mathrm{b}}$ \\
PB & $13,83^{\mathrm{a}}$ & $12,32^{\mathrm{b}}$ & $11,96^{\mathrm{b}}$ \\
$\mathrm{CZ}$ & $11,97^{\mathrm{a}}$ & $11,44^{\mathrm{b}}$ & $11,49^{\mathrm{b}}$ \\
\hline \\
Médias seguidas da mesma letra na linha não diferem significativamente \\
segundo o teste de Tukey $(\mathrm{P}>0,05)$.
\end{tabular}


A importância da proporção de FDN da forragem está associada não só com seu valor nutritivo como também com seu valor alimentar, pois está relacionada com o máximo consumo de matéria seca pelo animal (Mertens, 1994), relacionando-se à plantas com maiores teores de FDN um menor potencial de consumo.

Os teores de FDN variaram entre o mínimo de $58,46 \%$ na MS para o tratamento de alta intensidade de pastejo até o máximo de $72,74 \%$ na MS para o tratamento de baixa intensidade de pastejo (Tabela 6 e Figura1), estando de acordo com dados de literatura para o capim Tanzânia. Rego et al. (2001 a) encontraram teores de FDN que variaram entre 61,47 e $73,96 \%$ na MS, numa avaliação de diferentes alturas de manejo, no período de fevereiro a maio de 1999.

Os baixos teores de FDN encontrados nos três tratamentos podem estar associados à alta taxa de renovação de tecidos observada em todos os tratamentos, provavelmente decorrente da irrigação e da adubação nitrogenada.

Os menores teores de FDN para o tratamento de alta intensidade de pastejo podem também ser justificados pela maior renovação de tecidos deste tratamento em comparação aos demais. Segundo Santos et al. (2001) em abril/maio as hastes representavam cerca de $70 \%$ da massa de forragem, sendo que as três primeiras gerações de perfilhos foram responsáveis por 44 , 54 e $64 \%$ da produção de hastes nos tratamentos de alta, média e baixa intensidade de pastejo, respectivamente, nos seis primeiros ciclos de pastejo.

Os maiores teores de FDN foram observados nos primeiros ciclos de pastejo que correspondem ao período de primavera e verão, enquanto os menores teores de FDN são referentes aos ciclos de pastejo 7,8 e 9 correspondentes aos meses de junho a setembro (Figura 1). 
Tabela 6. Teores médios de FDN das quatro partes do capim Tanzânia em cada ciclo de pastejo.

\begin{tabular}{|c|c|c|c|}
\hline \multirow[b]{2}{*}{$\begin{array}{l}\text { Ciclo de } \\
\text { pastejo }\end{array}$} & \multicolumn{3}{|c|}{ Intensidade } \\
\hline & alta & média & baixa \\
\hline 1 & $6565^{\mathrm{a}}$ & $\begin{array}{r}\% \text { na MS } \\
6845^{\mathrm{a}}\end{array}$ & $6795^{2}$ \\
\hline 2 & $67.60^{\mathrm{a}}$ & $69,46^{a}$ & $68.93^{\circ}$ \\
\hline 3 & $67,62^{\mathrm{a}}$ & $69,22^{a}$ & $70.60^{\circ}$ \\
\hline 4 & $68.63^{a}$ & $69.58^{a}$ & $72.74^{\mathrm{a}}$ \\
\hline 5 & $68.05^{a}$ & $70.06^{a}$ & $70,16^{\mathrm{a}}$ \\
\hline 6 & $62,11^{a}$ & $65,85^{a}$ & $64,67^{2}$ \\
\hline 7 & $58,46^{\mathrm{a}}$ & $62,90^{b}$ & $62,97^{b}$ \\
\hline 8 & $59,10^{a}$ & $61,68^{a}$ & $60,97^{\circ}$ \\
\hline 9 & $59,56^{a}$ & $61,65^{a}$ & $62,80^{\circ}$ \\
\hline 10 & $66,47^{a}$ & $66,38^{a}$ & $67,54^{\circ}$ \\
\hline
\end{tabular}

A partir de abril (ciclo 6) nota-se um afastamento da curva referente ao tratamento de alta intensidade de pastejo em relação aos demais tratamentos (apesar de não haver significância à $5 \%$ pelo teste Tukey na diferença entre as médias, com exceção do $7^{\circ}$ ciclo de pastejo) (Tabela 6). Esse comportamento pode estar relacionado com o aumento significativo da proporção de hastes na massa de forragem a partir do ciclo 4 (Aguiar et al., 2001 c), intensificando o beneficio da maior renovação de tecidos. 


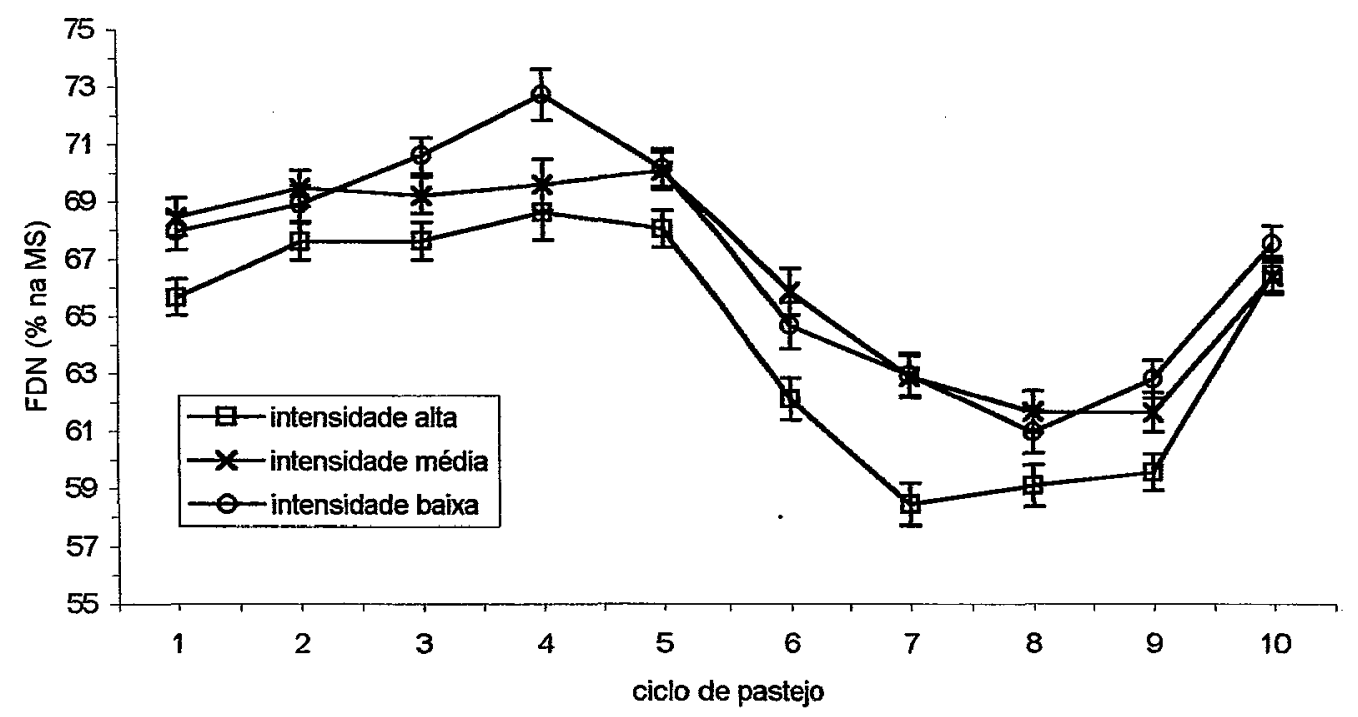

Figura 1 - Teores de FDN do capim Tanzânia nos dez ciclos de pastejo.

FDA apresentou comportamento semelhante a FDN. Os teores observados variaram entre o mínimo de $30,50 \%$ na MS para o tratamento de alta intensidade de pastejo, até $37,95 \%$ na MS no tratamento de baixa intensidade de pastejo (Tabela 7 e Figura 2).

A significância da diferença entre médias nos dez ciclos de pastejo avaliados, considerando-se o teste Tukey a $5 \%$, é restrita aos tratamentos de alta e baixa intensidade de pastejo, nos ciclos 3 e 7 , porém a diferença registrada do tratamento de alta intensidade de pastejo com relação aos demais ao considerar-se a média dos dez ciclos, parece bem representada pela curva dos três tratamentos (Figura 2). 
Tabela 7. Teores médios de FDA das quatro partes do capim Tanzânia em cada ciclo de pastejo.

\begin{tabular}{cccc}
\hline $\begin{array}{c}\text { Ciclo de } \\
\text { pastejo }\end{array}$ & alta & média & baixa \\
\hline 1 & $33,61^{\mathrm{a}}$ & $35,35^{\mathrm{a}}$ & $34,98^{\mathrm{a}}$ \\
2 & $35,22^{\mathrm{a}}$ & $36,54^{\mathrm{a}}$ & $36,33^{\mathrm{a}}$ \\
3 & $35,45^{\mathrm{a}}$ & $36,73^{\mathrm{ab}}$ & $37,75^{\mathrm{b}}$ \\
4 & $35,23^{\mathrm{a}}$ & $36,29^{\mathrm{a}}$ & $37,95^{\mathrm{a}}$ \\
5 & $35,18^{\mathrm{a}}$ & $36,88^{\mathrm{a}}$ & $37,13^{\mathrm{a}}$ \\
6 & $32,09^{\mathrm{a}}$ & $34,23^{\mathrm{a}}$ & $33,79^{\mathrm{a}}$ \\
7 & $30,50^{\mathrm{a}}$ & $32,43^{\mathrm{ab}}$ & $33,18^{\mathrm{b}}$ \\
8 & $30,56^{\mathrm{a}}$ & $31,73^{\mathrm{a}}$ & $31,57^{\mathrm{a}}$ \\
9 & $31,21^{\mathrm{a}}$ & $32,65^{\mathrm{a}}$ & $33,19^{\mathrm{a}}$ \\
10 & $34,63^{\mathrm{a}}$ & $34,99^{\mathrm{a}}$ & $35,40^{\mathrm{a}}$ \\
\hline Médias seguidas da mesma letra na linha não diferem \\
significativamente segundo o teste de Tukey (P>0,05).
\end{tabular}

Como para a FDN, os maiores teores de FDA foram observados nos primeiros ciclos de pastejo, diminuindo a partir de abril e atingindo os menores valores entre junho e setembro.

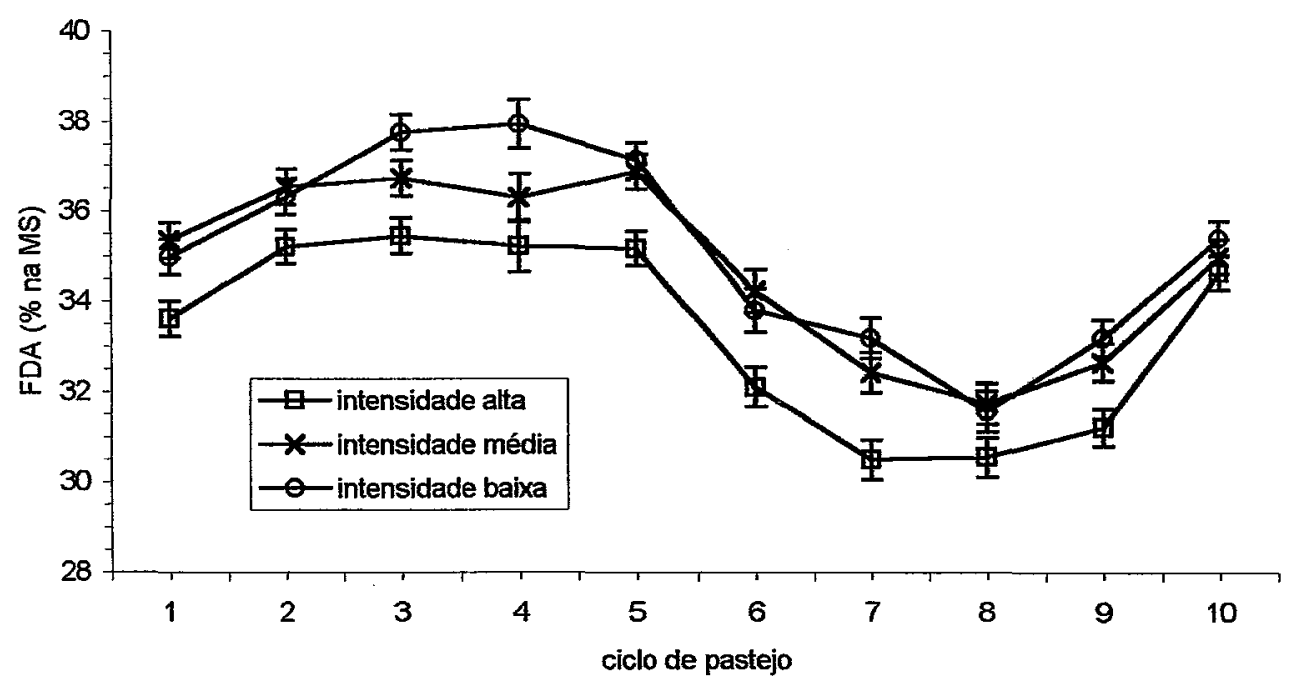

Figura 2 - Teores de FDA do capim Tanzânia nos dez ciclos de pastejo. 
Ao se observar os teores de FDN e FDA das quatro partes da planta que foram avaliadas (B, FN, FV e H) nota-se uma diferença de comportamento com a evolução dos ciclos de pastejo (Figuras 3 e 4 ).

O aumento da distância entre a curva referente aos teores de FDN (Figura 1) do tratamento de alta intensidade de pastejo e os demais tratamentos com o avanço dos ciclos de pastejo não é observado para as curvas referentes aos teores de FDA (Figura 2), o que pode estar relacionado à queda proporcionalmente mais intensa da concentração de FDN das hastes, que tem participação bastante elevada na massa de forragem a partir do ciclo 4 .

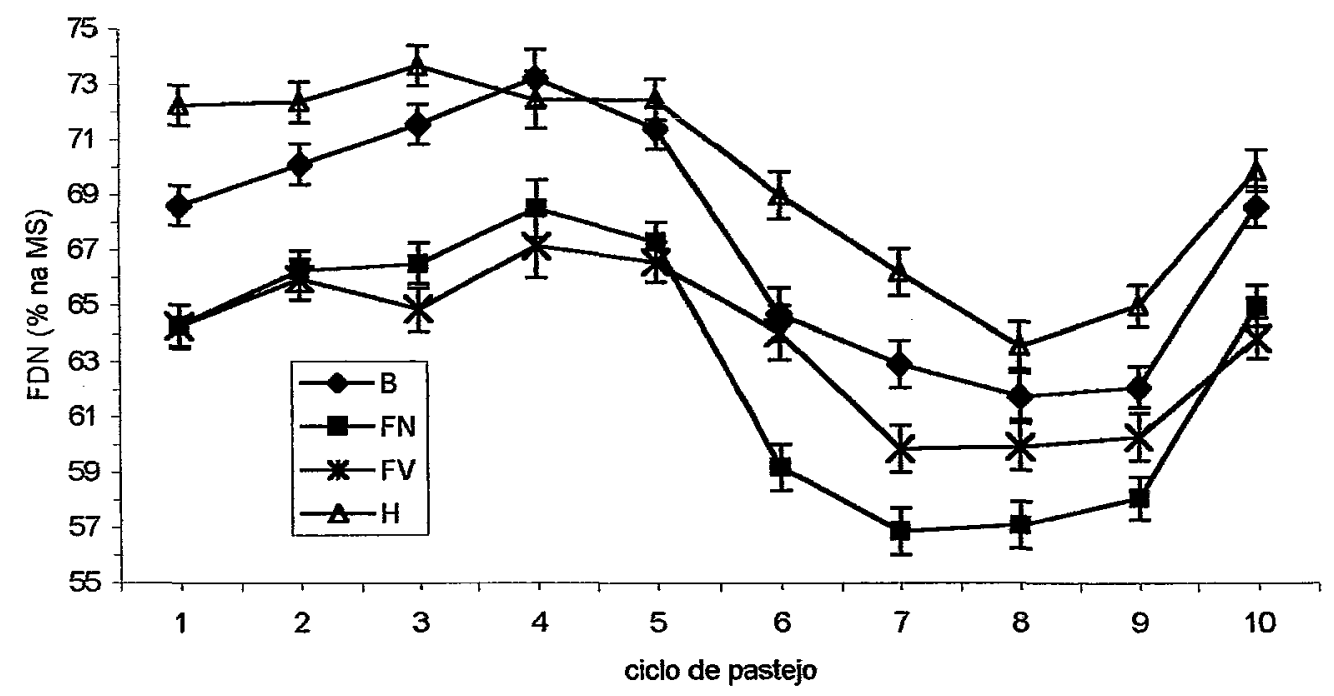

Figura 3 - Teores de FDN das quatro partes do capim Tanzânia, nos dez ciclos de pastejo. 


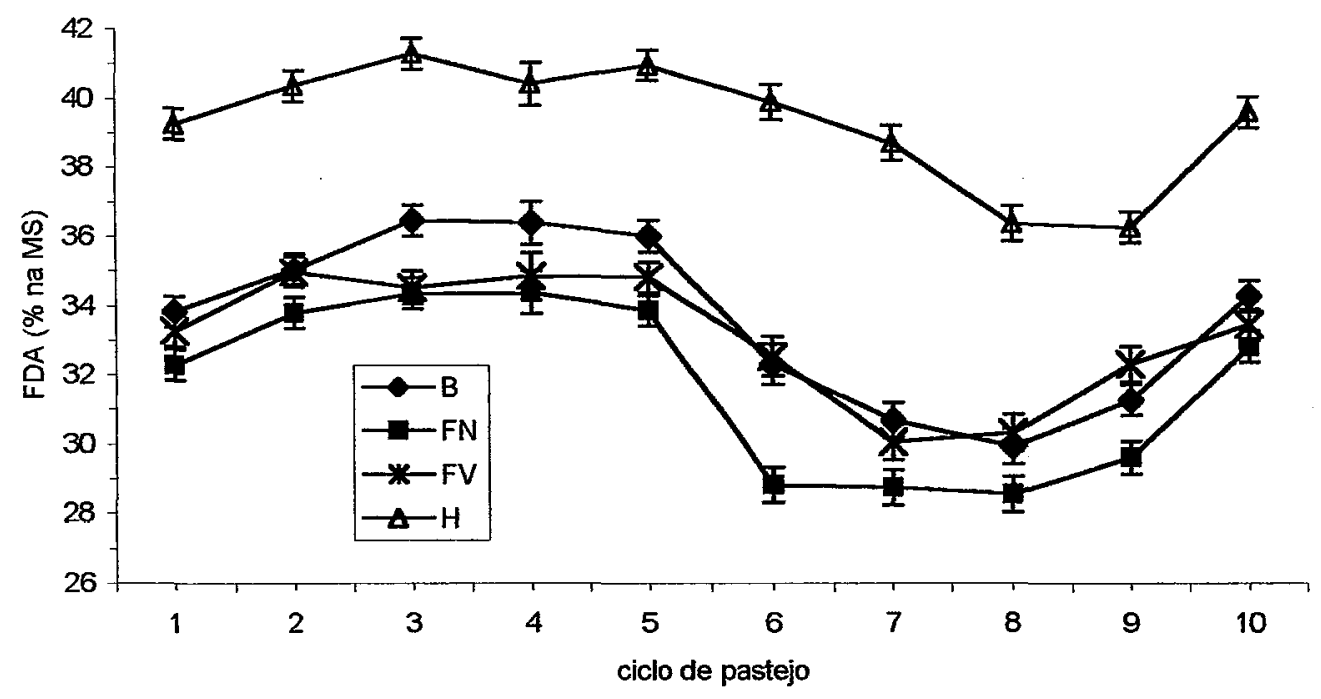

Figura 4 - Teores de FDA das quatro partes do capim Tanzânia, nos dez ciclos de pastejo.

Como citado anteriormente, outro aspecto importante a ser considerado é a relação lignina/FDN. Segundo Balsalobre (2002) trabalhando com as mesmas unidades experimentais, durante a mesma época, porém com amostras de pastejo simulado, o teor de lignina aumentou a partir do ciclo 6 (final de abril), o que pode acarretar grande variação na qualidade da planta, já que a época na qual encontrou-se menores teores de FDN coincide com a época na qual os maiores teores de lignina foram observados.

Quanto aos teores de PB novamente os tratamentos de média e baixa intensidade de pastejo, quando a média é referente às quatro partes da planta avaliadas e aos dez ciclos de pastejo, não mostraram diferença significativa. Porém, o tratamento de alta intensidade de pastejo acarretou teores superiores de PB (Tabela 5).

Para os três tratamentos houve aumento do teor de PB com o avanço dos ciclos de pastejo, comportamento este que deve ter sido profundamente influenciado pelo manejo adotado de adubação nitrogenada, já que a quantidade de nitrogênio aplicada a cada ciclo de pastejo foi a mesma ( $80 \mathrm{~kg}$ de N/ha). 
Nos ciclos de pastejo 7, 8 e 9 (início de junho a meados de setembro) a produção de matéria seca e de matéria seca verde (MSV) foi muito inferior à produção dos ciclos anteriores, principalmente se comparada aos ciclos 4, 5 e 6 (meados de fevereiro à início de junho) - chegando a atingir uma produção de $52 \%$ de MS e $29 \%$ de MSV em relação aos ciclos 4, 5 e 6, para o tratamento de alta intensidade de pastejo (Penati, 2002). Como os maiores teores de PB coincidem com os ciclos 7, 8 e 9 de pastejo (Figura 5), pode-se concluir que a manutenção da quantidade de $\mathrm{N}$, aplicado a cada ciclo de pastejo, deve ter propiciado significativo consumo de luxo deste nutriente quando a produção forrageira decresceu significativamente.

Os teores de PB variaram entre o mínimo de 9,00\% na MS, observado no ciclo 4 para o tratamento de baixa intensidade de pastejo, até o máximo de $18,51 \%$ na MS observado no ciclo 8 para o tratamento de alta intensidade de pastejo (Tabela 8).

Tabela 8. Teores médios de PB das quatro partes do capim Tanzânia em cada ciclo de pastejo.

\begin{tabular}{cccc}
\hline $\begin{array}{c}\text { Ciclo de } \\
\text { pastejo }\end{array}$ & alta & média & baixa \\
\hline 1 & $11,65^{\mathrm{a}}$ & $9,94^{\mathrm{a}}$ & $9,36^{\mathrm{a}}$ \\
2 & $10,55^{\mathrm{a}}$ & $9,98^{\mathrm{a}}$ & $10,68^{\mathrm{a}}$ \\
3 & $11,02^{\mathrm{a}}$ & $10,36^{\mathrm{a}}$ & $9,09^{\mathrm{a}}$ \\
4 & $11,72^{\mathrm{a}}$ & $11,32^{\mathrm{a}}$ & $9,00^{\mathrm{a}}$ \\
5 & $12,28^{\mathrm{a}}$ & $10,09^{\mathrm{a}}$ & $9,87^{\mathrm{a}}$ \\
6 & $14,93^{\mathrm{a}}$ & $12,31^{\mathrm{a}}$ & $13,47^{\mathrm{a}}$ \\
7 & $17,15^{\mathrm{a}}$ & $14,23^{\mathrm{b}}$ & $14,43^{\mathrm{ab}}$ \\
8 & $18,51^{\mathrm{a}}$ & $15,99^{\mathrm{a}}$ & $16,12^{\mathrm{a}}$ \\
9 & $18,14^{\mathrm{a}}$ & $16,60^{\mathrm{ab}}$ & $15,48^{\mathrm{b}}$ \\
10 & $12,35^{\mathrm{a}}$ & $12,42^{\mathrm{a}}$ & $12,10^{\mathrm{a}}$ \\
\hline Médias seguidas da mesma letra na linha não diferem \\
significativamente segundo o teste de Tukey (P>0,05).
\end{tabular}


Os valores encontrados na literatura apresentam uma grande variabilidade, aparentemente indicando uma elevada capacidade de assimilação das condições ambientais, refletindo grande variação deste parâmetro. Oliveira et al. (2001) avaliando a composição química de cinco gramíneas tropicais, entre elas o capim Tanzânia, em duas frequências de corte ( 30 e 45 dias), observaram teores de PB de 8,35 e 6,33\% na MS para 30 e 45 dias de crescimento respectivamente. Rego et al. (2001 a) avaliando diferentes alturas de corte para o capim Tanzânia, com frequência de corte de 28 dias, obtiveram valores entre 14,46 e $21,30 \%$ na MS de PB, sendo o aumento da altura do pasto relacionado aos menores teores de PB, assim como estratos superiores da planta associados à maiores teores deste parâmetro.

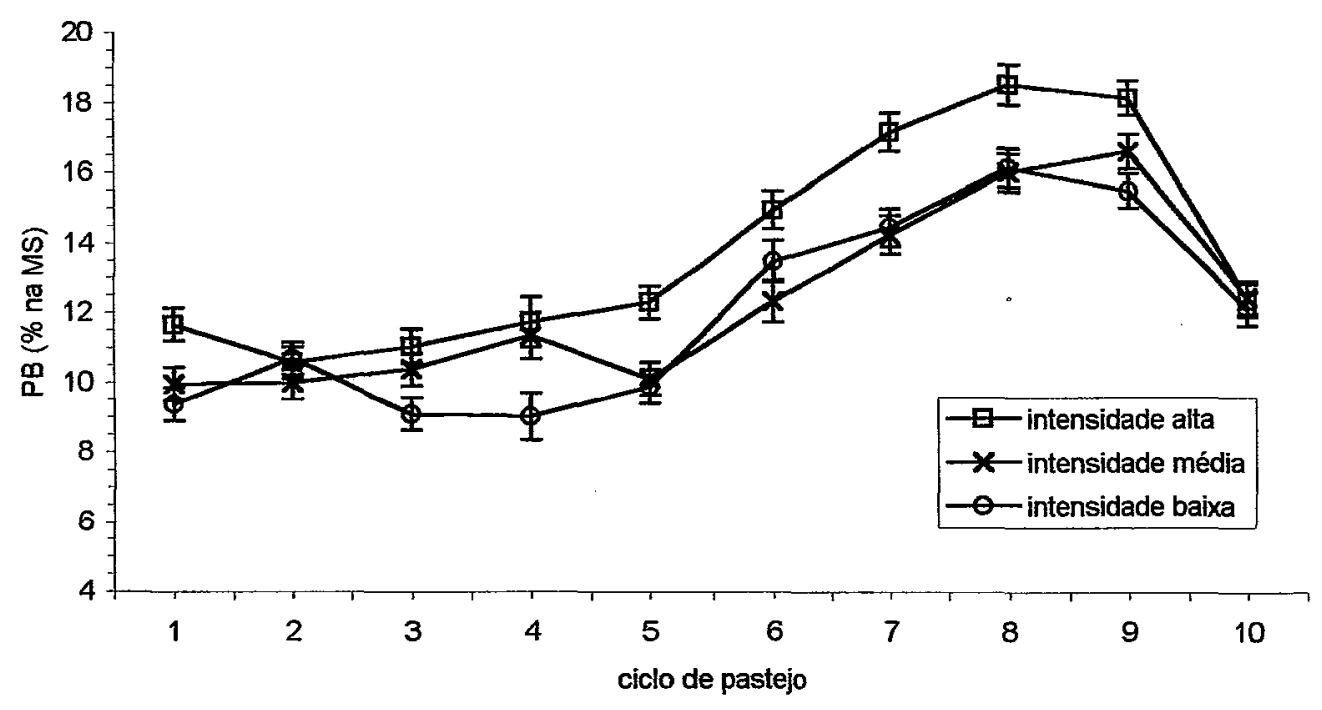

Figura 5 - Teores de PB do capim Tanzânia nos dez ciclos de pastejo.

As quatro partes da planta avaliadas mostraram comportamento semelhante ao longo dos ciclos de pastejo, apresentando elevação do teor de PB a partir do ciclo 6, com valores máximos para os ciclos 7, 8 e 9. As porções broto, folha nova e folha velha não se mostraram diferentes com relação aos 
teores de PB, sendo apenas a haste significativamente inferior para este parâmetro (Figura 6).

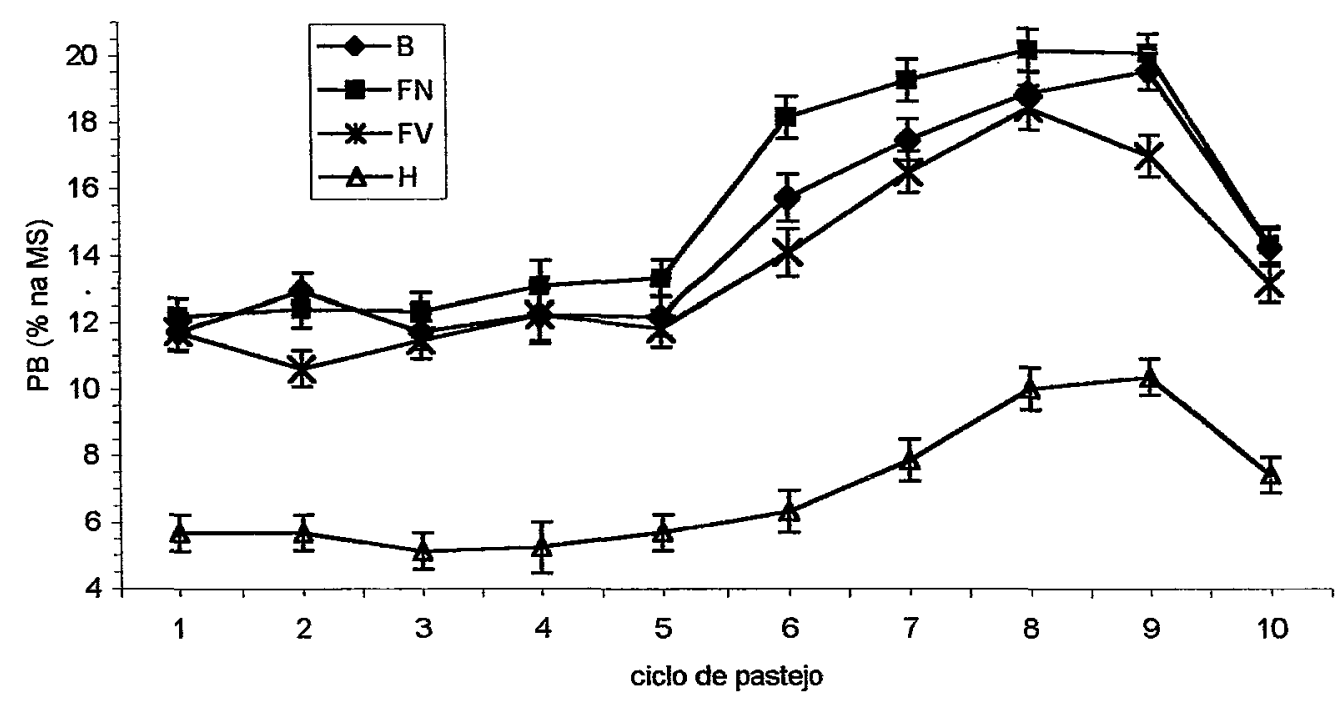

Figura 6 - Teores de PB das quatro partes do capim Tanzânia, nos dez ciclos de pastejo.

A partir do ciclo 5 de pastejo nota-se significativa elevação da qualidade bromatológica da forragem com relação aos teores de FDN, FDA e $\mathrm{PB}$, sendo que não apenas os elevados teores de PB mas também a redução dos teores de FDN e FDA, podem estar refletindo o manejo adotado de adubação nitrogenada. Belarmino et al. (2001) avaliando os teores de FDN e FDA do capim Tanzânia, para diferentes doses de aplicação de fósforo e nitrogênio, observaram que elevadas doses de nitrogênio diminuíram o teor de FDN da planta, e aumentaram o teor de FDA. Porém este aumento no teor de FDA pode estar relacionado à menor relação folha/caule observada nos tratamentos referentes às maiores doses de nitrogênio, devido à maior altura da planta. E este efeito pode ter sido minimizado ou mesmo suprimido com a elevada renovação de tecidos observada no ensaio gerador desta dissertação. 
Os teores de cinza observados se mostraram bastante elevados, variando entre 10,12 e 13,41\% na MS. Estes valores são coerentes com os altos teores de matéria mineral comuns à pastagens tropicais adubadas.

Tabela 9. Teores médios de $\mathrm{CZ}$ das quatro partes do capim Tanzânia em cada ciclo de pastejo.

\begin{tabular}{|c|c|c|c|}
\hline \multirow[b]{2}{*}{$\begin{array}{l}\text { Ciclo de } \\
\text { pastejo }\end{array}$} & \multicolumn{3}{|c|}{ Intensidade } \\
\hline & alta & média & baixa \\
\hline 1 & $10,94^{\mathrm{a}}$ & $\begin{array}{r}\% \text { na MS } \\
10,34 a\end{array}$ & $10,12 a$ \\
\hline 2 & $11,55^{\mathrm{a}}$ & $10,85 a$ & $11,35 a$ \\
\hline 3 & $11,36^{\mathrm{a}}$ & $11,56 a$ & $11,47 a$ \\
\hline 4 & $11,19^{a}$ & $11,23 a$ & $10,93 a$ \\
\hline 5 & $11,26^{\mathrm{a}}$ & $11,13 a$ & $10,74 a$ \\
\hline 6 & $12,57^{a}$ & $11,51 \mathrm{a}$ & $11,82 a$ \\
\hline 7 & $13,41^{a}$ & $12,34 a$ & $12,55 a$ \\
\hline 8 & $12,96^{\mathrm{a}}$ & $11,97 a$ & $12,53 a$ \\
\hline 9 & $13,05^{a}$ & $12,27 a$ & $12,18 a$ \\
\hline 10 & $11,38^{\mathrm{a}}$ & $11,22 \mathrm{a}$ & $11,20 \mathrm{a}$ \\
\hline
\end{tabular}

Nota-se uma elevação do teor de $\mathrm{CZ}$ a partir do ciclo 6 , coincidindo com o aumento do teor de PB e queda dos teores de FDN e FDA, podendo novamente estar relacionado ao manejo adotado de adubação. 


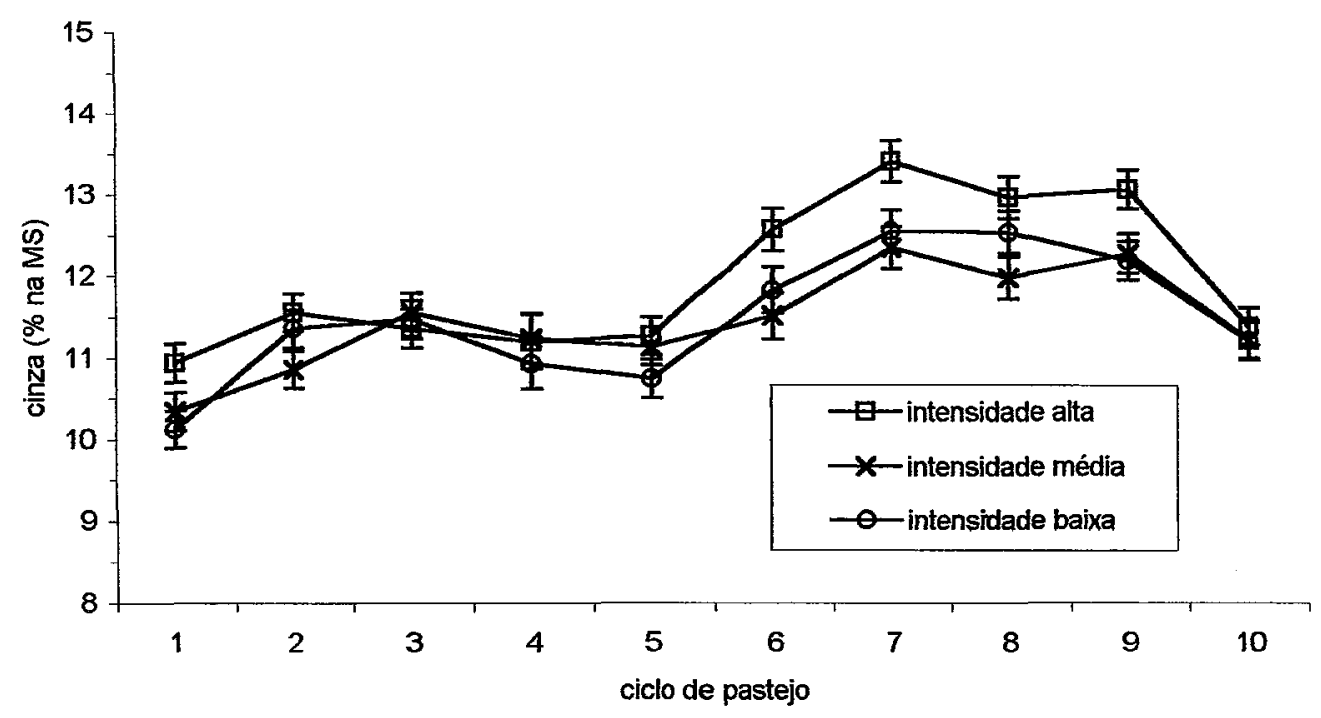

Figura 7 - Teores de CZ do capim Tanzânia nos dez ciclos de pastejo.

Variações na qualidade da forragem ao longo do ano foram observadas, incluindo diferenças relacionadas às intensidades de pastejo avaliadas. As diferenças associadas aos três tratamentos podem ser absorvidas por uma análise estatística menos rigorosa porém, é importante considerar que a qualidade bromatológica da planta em áreas irrigadas deve apresentar alterações mais discretas ao longo do ano, quando comparada à plantas de áreas não irrigadas.

É relevante também considerar que pequenas variações na qualidade bromatológica da planta podem acarretar grandes alterações na produtividade do sistema, refletindo em produção animal e alterando parâmetros econômicos. Porém outros fatores que influenciam a produtividade do sistema podem ter sua importância aumentada diante de variações muito discretas da qualidade bromatológica da planta, principalmente quando esta variação está contida em um intervalo de valores satisfatórios com relação à qualidade bromatológica da forragem. Pode-se, por exemplo, sugerir que características físicas da planta influenciaram significativamente o consumo de matéria seca pelos animais já que, apesar do tratamento de alta intensidade de pastejo ter se mostrado 
superior através da análise bromatológica, os ganhos de peso observados por Penati (2002) foram menores para este tratamento.

Os cinco bancos de dados geradores das equações de predição dos parâmetros bromatológicos avaliados, tiveram comportamento diferenciado com relação à qualidade da predição de tais parâmetros, porém apresentaram um comportamento similar quando a comparação é restrita a um determinado parâmetro bromatológico.

Como pode-se notar pela Tabela 10, SECV varia de 1,1357 a 1,7464 para FDN e de 0,9485 a 2,0773 para FDA, enquanto que para PB e CZ sua variação é de 0,3370 a 0,5215 e 0,3054 a 0,5120 respectivamente. $E$ a variação dos valores de $R^{2}$ é mais intensa para as equações de predição de FDN e FDA quando comparadas às equações referentes à $\mathrm{PB}$ e $\mathrm{CZ}$.

Para PB e CZ os cinco bancos de dados geraram boas equações, com valores baixos de SECV (máximo de 0,5215 para PB e 0,5120 para CZ), e valores altos de $R^{2}$ (mínimo de 0,9503 e 0,9516 para PB e CZ respectivamente). No entanto as equações de predição para FDN e FDA tiveram bons valores de $\mathrm{R}^{2}$, porém valores muito elevados de SECV. 
Tabela 10. Parâmetros considerados na avaliação das equações finais para FDN, FDA, PB e CZ.

\begin{tabular}{|c|c|c|c|c|c|c|}
\hline & $\begin{array}{l}\text { Banco de } \\
\text { dados* }\end{array}$ & $\mathbf{N}^{\prime}$ & SEC & $\mathrm{R}^{2}$ & SECV & 1-VR \\
\hline \multirow{5}{*}{ FDN } & B & 249 & 0,8773 & 0,9708 & 1,1357 & 0,9514 \\
\hline & A & 635 & 1,5026 & 0,9831 & 1,6634 & 0,9792 \\
\hline & $E$ & 1328 & 1,6396 & 0,9707 & 1,7464 & 0,9668 \\
\hline & D & 119 & 1,2098 & 0,9419 & 1,6448 & 0,8929 \\
\hline & C & 388 & 1,5063 & 0,8574 & 1,6039 & 0,8390 \\
\hline \multirow{5}{*}{ FDA } & B & 251 & 0,8913 & 0,9634 & 0,9485 & 0,9595 \\
\hline & $E$ & 1257 & 1,2335 & 0,9744 & 1,2941 & 0,9718 \\
\hline & A & 657 & 1,8981 & 0,9624 & 2,0773 & 0,9550 \\
\hline & D & 117 & 0,9928 & 0,9277 & 1,2668 & 0,8816 \\
\hline & C & 376 & 0,9108 & 0,8910 & 0,9813 & 0,8739 \\
\hline \multirow{5}{*}{ PB } & B & 172 & 0,2367 & 0,9965 & 0,3370 & 0,9929 \\
\hline & $E$ & 1250 & 0,4171 & 0,9948 & 0,4374 & 0,9943 \\
\hline & A & 646 & 0,3748 & 0,9726 & 0,4068 & 0,9678 \\
\hline & C & 377 & 0,4379 & 0,9875 & 0,4932 & 0,9842 \\
\hline & D & 116 & 0,4820 & 0,9503 & 0,5215 & 0,9413 \\
\hline \multirow{4}{*}{$\mathrm{CZ}$} & D & 113 & 0,3294 & 0,9846 & 0,4417 & 0,9723 \\
\hline & A & 582 & 0,2805 & 0,9516 & 0,3054 & 0,9426 \\
\hline & B & 219 & 0,3098 & 0,9599 & 0,4740 & 0,9067 \\
\hline & $E$ & 1014 & 0,4909 & 0,9675 & 0,5120 & 0,9646 \\
\hline
\end{tabular}

Alguns autores propõem, através de ensaios que avaliam a determinação da composição química de forragens via NIRS, que a calibração através de bancos de dados de forragens da mesma espécie da amostra que deve ter sua composição química predita pela equação, são mais acuradas que calibrações feitas com várias espécies de forragens (Shenk e Westerhaus, 1993; Fontaneli et al., 2001).

Porém é unânime na literatura que o aumento do número de amostras geradoras da equação acompanhado do aumento da variabilidade espectral do 
conjunto é a melhor ferramenta para melhorar a equação, tornando mais preciso o valor predito.

Desconsiderando o número de amostras utilizadas para gerar a equação de predição ( $N^{\prime}$ ) nota-se que o banco de dados $B$ se mostrou superior em relação aos demais na predição de FDN, FDA e PB, apresentando a melhor composição entre altos valores de $R^{2}$ e 1-VR, e baixos valores de SEC e SECV, assim como o banco de dados $\mathrm{D}$ se mostrou superior na predição de $\mathrm{CZ}$. Porém o número de amostras que compõe o banco de dados é claramente uma característica de elevada importância da equação.

Fontaneli et al. (2001) avaliando a composição química do capim bermuda pela técnica NIRS, consideraram as equações obtidas por eles de excelente resolução, sendo que o valor máximo de SECV foi 0,64 , o valor mínimo de $\mathrm{R}^{2}$ 0,72 e o número de amostras utilizadas para compor as equações variou entre 120 e 128.

No processo de construção das equações além da aplicação de vários tratamentos matemáticos, como citado anteriormente, foram construídos bancos de dados compostos por associações parciais dos bancos de dados $A$, B, C e D. Tal avaliação revelou grande benefício proporcionado não apenas pelo aumento de $\mathrm{N}$ ' como também pelo aumento da variabilidade espectral do banco de dados. Além disso, o aumento de $\mathrm{N}^{\prime}$ decorrente da associação de amostras de diferentes origens, se mostrou mais efetivo quando a variabilidade espectral dos conjuntos de amostras distintas pertencia a um intervalo comum, comportamento este bem representado pelas equações geradas pelo banco de dados $\mathrm{E}$. 


\section{CONCLUSÕES}

A avaliação bromatológica da planta indicou melhor qualidade, caracterizada por menores valores de FDN e FDA, e maiores valores de PB, quando a forragem foi manejada com baixo resíduo pós pastejo, porém outros aspectos (como características físicas da planta) devem ser considerados para se optar pelo resíduo mais adequado a cada sistema de produção.

Os três tratamentos apresentaram baixos valores de FDN.

Mantendo-se a quantidade de $\mathbf{N}$ aplicada a cada ciclo de pastejo, provavelmente propiciou-se significativo consumo de luxo deste nutriente quando a produção forrageira decresceu, justificando os altos teores de PB encontrados no período de inverno.

A técnica NIRS se mostrou satisfatória para predizer parâmetros bromatológicos e a associação de plantas distintas, para compor o banco de dados gerador das equações de predição, trouxe benefícios quando os vários conjuntos de amostras de mesmo gênero ou espécie, que compunham o banco de dados, possuiam variabilidade espectral pertencente a um intervalo comum. 


\section{REFERÊNCIAS BIBLIOGRÁFICAS}

ABRAHÃO, J.J.S. Valor nutritivo de plantas forrageiras. In: MONTEIRO, A.L.; MORAES, A.; CORREA, E.A.S. et al. Forragicultura no Paraná. Londrina: CPAF, 1996. p.93-108.

ABRAMS, S. M. Sample preparation. In: ESTADOS UNIDOS. Department of Agriculture. Near infrared reflectance spectroscopy (NIRS): analysis of forage quality. Washington: USDA, 1989. (USDA. Agricultural Handbook, 643).

AGUIAR, A.P.A.; AMARAL, G.C.; DATENA, J.L.F. et al. Produtividade de carne em sistemas intensivos nas pastagens de Mombaça, Tanzânia e Tifton 85 na região do Cerrado. In: REUNIÃO ANUAL DA SOCIEDADE BRASILEIRA DE ZOOTECNIA, 38., Piracicaba, 2001. Anais. Piracicaba: FEALQ, 2001a. p.1461-1462.

AGUIAR, A.P.A.; ALMEIDA, B.H.P.J.F.; AMARAL, G.C. et al. Viabilidade econômica da produção de carne em sistemas intensivos de pastagens na região do Cerrado. In: REUNIÃO ANUAL DA SOCIEDADE BRASILEIRA DE ZOOTECNIA, 38., Piracicaba, 2001. Anais. Piracicaba: FEALQ, 2001b. p.1462-1464.

AGUIAR, S.V.H.; BALSALOBRE, M.A.A.; LABONIA, V.D.S. et al. Proporção de partes morfológicas do capim Tanzânia (Panicum maximum Jacq) em três intensidades de pastejo ao longo do ano. In: REUNIÃO ANUAL DA SOCIEDADE BRASILEIRA DE ZOOTECNIA, 38., Piracicaba, 2001. Anais. Piracicaba: FEALQ, 2001c. p.342-343.

ALMEIDA, E.X.; MARASCHIN, G.E.; HARTHMANN, D.E.L. et al. Oferta de forragem de capim- elefante anão 'Mott' e o rendimento animal. Revista da Sociedade Brasileira de Zootecnia, v.29, n.5, p.1288-1295, 2000. 
AGUIAR, A.P.A.; AMARAL. G.C.; DATENA, J.L. et al. Possibilidades de produção de carne em sistemas intensivos de pastagens tropicais com animais de raças zebuínas. In: CONGRESSO BRASILEIRO DAS RAÇAS ZEBUINAS, Uberaba, 2000. Anais. Uberaba: ABCZ, 2000. p.350-352.

BALSALOBRE, M.A.A. Desempenho de vacas em lactação sob pastejo rotacionado de Capim-elefante (Pennisetum purpureum Schum.). Piracicaba, 1996. 139 p. Dissertação (Mestrado) - Escola Superior de Agricultura "Luiz de Queiroz", Universidade de São Paulo.

BALSALOBRE, M.A.A. Valor alimentar do capim Tanzânia irrigado. Piracicaba, 2002. 113 p: Tese (Doutorado) - Escola Superior de Agricultura "Luiz de Queiroz", Universidade de São Paulo.

BARBOSA, M.A.A.F.; NASCIMENTO JUNIOR, D.; CECATO, $U$. et al. Desempenho de novilhos em capim Tanzânia com diferentes ofertas de forragem. In: REUNIÃO ANUAL DA SOCIEDADE BRASILEIRA DE ZOOTECNIA, 38., Piracicaba, 2001. Anais. Piracicaba: FEALQ, 2001. p.287-288.

BARBOSA, R.A.; EUCLIDES, V.P.B.; NASCIMENTO JÚNIOR, D. et al. Morfogênese do capim Tanzânia em duas intensidades de pastejo. In: REUNIÃO ANUAL DA SOCIEDADE BRASILEIRA DE ZOOTECNIA, 38., Piracicaba, 2001. Anais. Piracicaba: FEALQ, 2001. p.95-96.

BELARMINO, M.C.J.; PINTO, J.C.; ROCHA, G.P. et al. Teores de FDN e FDA na forragem de Panicum maximum Jacq. cv. Tanzânia $i$ em função da aplicação de doses de fósforo e nitrogênio. In: REUNIÃO ANUAL DA SOCIEDADE BRASILEIRA DE ZOOTECNIA, 38., Piracicaba, 2001. Anais. Piracicaba: FEALQ, 2001. p.252-253.

BEM GERA, I.; NORRIS, K.H. Determination of moisture content in soybeans by direct spectrophotometry. Journal of Agricultural Research, v.18, n.3, p.125-132, 1968.

BURLISON, A.J.; HODGSON, J.; ILLIUS, A.W. Sward canopy structure and the bite dimension and bite weight of grazing sheep. Grass and Forage Science, v.46, p.29-38, 1991.

CORSI, M. Manejo de plantas forrageiras do gênero Panicum. In: PEIXOTO, A.M.; MOURA, J.C.; FARIA, V.P. Plantas forrageiras de pastagens. Piracicaba: FEALQ, 1995. p.17-35. 
CORSI, M. Effects of nitrogen rates and harvesting interval on dry matter productivity, tillering and quality of the tropical grass Panicum maximum (Jacq.). Ames, 1984. 125 p. Tese (PhD) - Ohio State University.

COWE, I.A.; McNICOL, J.W. The use of principal components in the analysis of near-infrared spectra. Applied Spectroscopy, v.39, n.2, p.257-265, 1985.

CORSI, M. Pastagens de alta produtividade. In: CONGRESSO BRASILEIRO DE PASTAGENS, Piracicaba, 1986. Anais. Piracicaba: FEALQ, 1986. p.499-512.

CORSI, M.; MARTHA JR., G.B.; NASCIMENTO JÚNIOR, D. et al. In: INTERNACIONAL GRASSLAND CONGRESS, 19., São Pedro, 2001. Proceedings. Piracicaba: FEALQ, 2001. p.801-806.

CARVALHO, P.C.F.; RIBEIRO FILHO, H.M.N.; POLI, C.H.E. et al. Importância da estrutura da pastagem na ingestão e seleção de dietas pelo animal em pastejo. In: MATTOS, W.R.S. (Ed.). A produção animal na visão dos brasileiros. Piracicaba: FEALQ, 2001. p.853-871.

ESTEVES, S.N. Custo de produção de carne usando pastagens adubadas. In: SIMPÓSIO SOBRE MANEJO E NUTRIÇÃO DE GADO DE CORTE, Goiânia, 2000. Anais. Goiânia: CBNA, 2000. p.25-41.

GERDES, L.; WERNER, J.C.; COLOZZA, M.T. et al. Avaliação de características das gramíneas forrageiras Marandu, Setária e Tanzânia nas estações do ano. Revista Brasileira de Zootecnia, v.29, n.4, p.955-963, 2000.

HALIN, R.A.; BUXTON, D.R.; HATTENDORF, M.J. et al. Water stress effects on alfafa forage quality after adjustment for maturity differences. Agronomy Journal, v.81, p.189-194, 1989.

HODGSON, J.; CLARK, D.A.; MITCHELL, R.J. Foraging behavior in grazing animals and its impact on plant communities. In: FAHEY JR., G.C.; COLLINS, M.; MERTENS, D.R. et al. Forage quality, evaluation and utilization. Madison: ASA; CSSA; SSSA, 1994. cap.19, p.796-827.

HOLMES, C.W.; WILSON, G.F. Milk production from pasture. London: Butterworths, 1984. 319p.

HYMOVITZ, T.; DUDLEY, J.W.; COLLINS, F.I. et al. Estimation of protein and oil concentration in corn, soybean, and oat seed by near infrared light reflectance. Crop Science, v.14, p.713-715, 1974. 
JANK, L. Melhoramento e seleção de variedades de Panicum maximum. In: SIMPÓSIO SOBRE MANEJO DA PASTAGEM, 12., Piracicaba, 1995. Anais. Piracicaba: FEALQ, 1995. p.21-58.

JANK, L.; SAVIDAN, Y.; SOUZA, M.T. et al. Avaliação do germoplasma de Panicum maximum introduzido da África. 1. Produção forrageira. Revista da Sociedade Brasileira de Zootecnia, v.23, p.433-440, 1994.

KOWALSKI, B.R. Chemometrics: theory and applications. In: WILLIANS, P.; NORRIS, K. (Ed.). Near infra-red technology in the agricultural and food industries. Washington: American Chemical Society, 1977. (ACS. Symposium Series, 52).

LEMAIRE, G.; CHAPMAN, D. Tissue flows in grazed plant communities. In: HODGSON, J.; ILLIUS, A.W. The ecology and management of grazing systems. London: CAB International, 1996. p.3-36.

MENEZES, M.J.T.; MARTHA JR., G.B.; PENATI, M.A. et al. Efeito da época de adubação nitrogenada do capim Tanzânia irrigado após a desfolha sobre o peso e número de perfilhos. In: REUNIÃO ANUAL DA SOCIEDADE BRASILEIRA DE ZOOTECNIA, 38., Piracicaba, 2001. Anais. Piracicaba: FEALQ, 2001a. p.348-349.

MENEZES, M.J.T.; MARTHA JR., G.B.; PENATI, M.A. et al. Produtividade do capim Tanzânia irrigado em resposta à época de adubação nitrogenada após a desfolha. In: REUNIÃO ANUAL DA SOCIEDADE BRASILEIRA DE ZOOTECNIA, 38., Piracicaba, 2001. Anais. Piracicaba: FEALQ, $2001 \mathrm{~b}$. p.349-351.

MERTENS, D.R. Regulation of forage intake. In: FAHEY JR., G.C.; COLLINS, M.; MERTENS, D.R. et al. Forage quality, evaluation and utilization. Madison: ASA, CSSA, SSSA, 1994. cap.11, p.450-493.

MITCHELL, R.J.; HODGSON, J.; CLARK, D.A. The independence effects of sward height and bulk density on the bite parameters of Romney ewes and red deer hinds. In: INTERNATIONAL GRASSLAND CONGRESS, 17., Palmerston North, 1993. Proceedings. Palmerston North: Massey University, 1993. p.704-706.

NORRIS, K.H.; HART, J.R. Direct spectrophotometric determination of moisture content of grain and seeds. In: INTERNATIONAL SYMPOSIUM OF PRINCIPLES AND METHODS OF MEASURING MOISTURE IN LIQUIDS AND SOLIDS. HUMIDITY AND MOISTURE, 1965. Proceedings. v.4, p.19. 
NORRIS, K.H.; WILLIAMS, P.C. Optimization of mathematical treatments of raw near-infrared signal in the measurement of protein in hard red spring wheat. I. Influence of particle size. Cereal Chemistry, v.61, n.12, p.158$165,1984$.

NORRIS, K.H.; BARNES, R.F.; MOORE, J.E. et al. Predisting forage quality by infrared reflectance spectroscopy. Journal of Animal Science, v.43, n.4, p.889-897, 1976.

OLIVEIRA, T.N.; CARVALHO, M.V.B.A.; SILVA, A.L.C. et al. Composição química de gramíneas tropicais submetidas a duas frequências de corte. In: REUNIÃO ANUAL DA SOCIEDADE BRASILEIRA DE ZOOTECNIA, 38., Piracicaba, 2001. Anais. Piracicaba: FEALQ, 2001. p.107-109.

PEDREIRA, C.G.S.; MELLO, A.C.L. Cynodon spp. In: SIMPÓSIO SOBRE MANEJO DA PASTAGEM, 17., Piracicaba, 2000. Anais. Piracicaba: FEALQ, 2000. p.109-134.

PENATI, M.A. Estudo do desempenho animal e produção do capim Tanzânia (Panicum maximum, Jacq.) em um sistema rotacionado de pastejo sob irrigação em três níveis de resíduo pós pastejo. Piracicaba, 2002. 117 p. Tese (Doutorado) - Escola Superior de Agricultura "Luiz de Queiroz", Universidade de São Paulo.

PIRES, F.F. Utilização da técnica da espsctrofotometria de reflectância no infravermelho proximal na predição da composição química da Alfafa (Medicago sativa, L.). Porto Alegre, 1996. 81 p. Dissertação (Mestrado) Faculdade de Agronomia, Universidade Federal do Rio Grande do Sul.

PITOMBO, L.H. Pecuária em números. DBORural, v.17, n.219, p.26-80, jan./fev., 1999.

QUADROS, D.G. Produção e perdas de forragem em pastagens dos cultivares Tanzânia e Mombaça de Panicum maximum Jacq. adubadas com doses crescentes de NPK. Jaboticabal, 2001. 83 p. Dissertação (Mestrado) Faculdade de Ciências Agrárias e Veterinária, Universidade Estadual Paulista "Júlio de Mesquita Filho".

RÉGO, F.; CECATO, U.; CANTO, M.W. et al. Qualidade do capim Tanzânia (Panicum maximum Jacq. cv. Tanzânia 1) manejado em diferentes alturas, sob pastejo. In: REUNIÃO ANUAL DA SOCIEDADE BRASILEIRA DE ZOOTECNIA, 38., Piracicaba, 2001. Anais. Piracicaba: FEALQ, 2001a. p.117-118. 
RÉGO, F.; CECATO, U.; CANTO, M.W. et al. Estudo de características morfológicas e índice de área foliar do capim Tanzânia (Panicum maximum Jacq. cv. Tanzânia 1) manejado em diferentes alturas, sob pastejo. In: $38^{\mathrm{a}}$ REUNIÃO ANUAL DA SOCIEDADE BRASILEIRA DE ZOOTECNIA, Piracicaba, 2001. Anais. Piracicaba: FEALQ, 2001b. p.118-120.

RINNE, R.W.; GIBSON, S.; BRADLEY, J.; SEIF, R.; BRIM, C.A. Soybean protein and oil percentages determined by infrared analysis. Washington: USDA, 1975. (Agricultural Research Publication, ARS-NC-26).

SANTOS, P.M. Estudo de algumas características agronomicas de Panicum maximum (Jacq.) cvs. Tanzânia e Mombaça para estabelecer seu manejo. Piracicaba, 1997. Dissertação (Mestrado) - Escola Superior de Agricultura "Luiz de Queiroz", Universidade de São Paulo.

SANTOS, P.M. Controle do desenvolvimento das hastes no capim Tanzânia: um desafio. Piracicaba, 2002. 98 p. Tese (Doutorado) - Escola Superior de Agricultura "Luiz de Queiroz", Universidade de São Paulo.

SANTOS P.M.; BALSALOBRE, M.A.A.; CORSI, M. Participação de gerações de perfilhos na produção de capim Tanzânia. In: REUNIĀO ANUAL DA SOCIEDADE BRASILEIRA DE ZOOTECNIA, 38., Piracicaba, 2001. Anais. Piracicaba: FEALQ, 2001. p.123-124.

SAVIDAN, Y.H.; JANK, L.; COSTA, J.C.G. Registro de 25 acessos selecionados de Panicum maximum. Campo Grande: EMBRAPA, CNPGC, 1990. 68 p. (EMBRAPA. CNPGC. Documentos, 44).

SHENK, J.S.; WESTERHAUS, M.O. The application of near infrared reflectance spectroscopy (NIRS) to forage analisys. In: FAHEY JR, G.C. Forage quality, evaluation, and utilization. Madison: ASA, 1994. p.406-449.

SHENK, J.S.; WORKMAN J.R.; WESTERHAUS, M.O. Application of NIR Spectroscopy to Agricultural Products. In: BURNS, D.A.; CIURCZAK, E.W. Handbook of near infrared analisys. New York, 1992. p.383-431.

SAS INSTITUTE. SAS User's guide: statistics. Cary, 1990. 956p.

TWIDWELL, E.K.; JOHNSON, K.D.; CHERNEY, J.H.; VOLENEC, J.J. Forage quality and digestion kinetics of Switchgrass herbage and morphological components. Crop Science, v.28, p.778-82, 1988. 
TEMPLETON JR., W.C.; SHENK, J.S.; NORRIS, K.H. Forage analisys with near-infrared reflectance spectroscopy: status and outline of National Research Project. In: INTERNATIONAL GRASSLAND CONGRESS, 14, 1983. Proceedings. p.528-531.

VAN SOEST, P.J. Nutritional ecology of the ruminant. Ithaca: Cornell University press, 1982 . $374 p$.

VOUGH, L.R.; MARTEN, G.C. Influence of soil moisture and ambient temperature on yield and quality of alfafa forage. Agronomy Journal, v.63, p.40-42, 1971.

VOGEL, A.I. Analise química quantitativa. 5. ed. Rio de Janeiro: Guanabara Koogan, 1992. 712p.

VIEIRA, R.A.M.; PEREIRA, J.C.; MALAFAIA, P.A.M. Fracionamento dos carboidratos e cinética de degradação in vitro da fibra em detergente neutro da extrusa de bovinos a pasto. Revista Brasileira de Zootecnia, v.29, n.3, p.889-897, 2000.

WILLIANS, P.C. Application of near infrared reflectance spectroscopy to analysis of cereal grains and oilseeds. Cereal Chemistry, v.52, p.561-576, 1975.

WILLIANS, P.C. Samples, sample preparation, and sample selection. In: BURNS, D. A.; CIURCZAK, E. W. Handbook of near infrared analysis. New York, 1992. p.281-315. 